Research Paper

\title{
Specificity and biologic activities of novel anti-membrane IgM antibodies
}

\author{
Rachel S. Welt ${ }^{1}$, Jonathan A. Welt ${ }^{2}$, David Kostyal ${ }^{3}$, Yamuna D. Gangadharan², \\ Virginia Raymond ${ }^{2,4}$ and Sydney Welt ${ }^{2}$ \\ ${ }^{1}$ American Museum of Natural History, New York, NY, USA \\ 2 Welt Bio-Molecular Pharmaceutical, LLC., Armonk, NY, USA \\ ${ }^{3}$ ARDL, Inc., Akron, OH, USA \\ ${ }^{4}$ Biogent, LLC., Armonk, NY, USA \\ Correspondence to: Sydney Welt, email: welt.bmp@gmail.com \\ Keywords: monoclonal antibody, membrane IgM, B-cell receptor, leukemia, lymphoma \\ Received: January 31, $2016 \quad$ Accepted: September 24, $2016 \quad$ Published: October 09, 2016
}

\section{ABSTRACT}

The concept that the B-cell Receptor (BCR) initiates a driver pathway in Iymphoma-leukemia has been clinically validated. Previously described unique BCR Ig-class-specific sequences (proximal domains (PDs)), are not expressed in serum Ig (sIg). As a consequence of sequence and structural differences in the membrane IgM (mIgM) $\mu$-Constant Domain 4, additional epitopes distinguish mIgM from sIgM. mAbs generated to linear and conformational epitopes, restricted to $\mathrm{mIgM}$ and not reacting with sIgM, were generated despite the relative hydrophobicity of the PDm sequence. Anti-PD mAbs (mAb1, mAb2, and mAb3) internalize mIgM. Anti-mIgM mAb4, which recognizes a distinct non-ligand binding site epitope, mediates $\mathrm{mIgM}$ internalization, and in low-density cultures, growth inhibition, anti-clonogenic activity, and apoptosis. We show that mAb-mediated $\mathrm{mIgM}$ internalization generally does not interrupt BCRdirected cell growth, however, mAb4 binding to a non-ligand binding site in the $\mathrm{mIgM}$

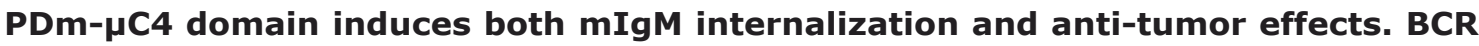
micro-clustering in many B-cell leukemia and lymphoma lines is demonstrated by SEM micrographs using these new mAb reagents. mAb4 is a clinical candidate as a mediator of inhibition of the BCR signaling pathway. As these agents do not bind to non-mIgM B-cells, nor cross-react to non-lymphatic tissues, they may spare B-cell/ normal tissue destruction as mAb-drug conjugates.

\section{INTRODUCTION}

The B-cell Receptor Complex (BCRC) emerged as a molecular target for the therapy of leukemia and lymphoma with the advent of personalized anti-idiotype (anti-id) monoclonal antibody (mAb) technology [1, 2]. Complementarity determining regions (CDRs) of cell surface membrane-Immumoglobulins ( $\mathrm{mIg}$ ) were recognized as both patient-unique "tumor specific" targets and as the critical regulatory element in the neoplastic process [3-8]. A "proof-of-principle" clinical study published in 1998 demonstrated that patientspecific, custom made anti-id mAbs, given alone or with other agents, induced objective measurable and durable responses [8]. Of note in this report was that patients in prolonged clinical remission harbored "dormant tumor cells" detectable by PCR [8]. These findings suggest that anti-id therapy can induce lineage-specific celldifferentiation and/or pathway regulatory effects [8].

An investigation of the mechanisms of anti-id resistance demonstrated that $\mathrm{CDR}$ sequence mutation variants, rather than loss of the $\mathrm{mIg}$ structure, were responsible for treatment failure [9-11]. Thus, signaling emanating from the BCRC with new mutated CDRs was responsible for persistence of the malignant phenotype. Subsequently, molecular studies demonstrated that Chronic Lymphocytic Leukemia (CLL) B-cells were in a constitutively activated state, recapitulating normal receptor-antigen-mediated activation, leading to proliferation and differentiation programs normally initiated by the BCRC $[12,13]$. The complexity of these initiating activation steps is further emphasized by the 
observation that BCRC signaling can also be propagated through non-Immune-receptor Tyrosine-based Activation Motifs (ITAM) or by endocytosed receptors [14-15]. These findings support the contention that anti-id mAbs modulate tonic BCRC-mediated B-cell signaling leading to differentiation of malignant cells, dormancy, and/or induction of apoptosis [3-8]. Based on these observations, key downstream pathways of the BCRC have been identified and small molecule tyrosine kinase inhibitors (TKI) have been developed. The robust anti-tumor effects of these agents have now been demonstrated in clinical trials and provide "proof-of-principle" in support of the hypotheses regarding the central role of BCRC signaling in the molecular biology of B-cell malignancies [16-20]. Therefore, the development of additional agents to control the constitutively activated BCRC signaling is warranted, especially those targeting the BCR itself.

As a consequence of mIgM sequence homology to serum IgM (sIgM), specific B-cell mIgM targeting in vivo was thought not to be feasible, except for the anti-id, patient-specific CDR approach. However, the subsequent finding of unique class-specific sequences identified in $\mathrm{mIg}$ receptors, designated as "proximal domains" (PDs), that are not contained in the corresponding secreted Ig protein sequences (mRNA splice variants) (Genbank), opened new discovery pathways. These PD sequences represent potential cell surface epitope targets specific to each Ig class. mAbs reacting with the $\mathrm{mIgE} P D$ have been demonstrated to induce apoptosis [21]. Thus, the PD may be critical in transmitting $\mathrm{mIg}$ receptor transmembranesignaling to the closely associated CD $79 \alpha / \beta$ cytoplasmic tyrosine kinase (TK), and anti-PD mAbs may, in general, be able to modulate signaling [21]. This concept that $\mathrm{mAbs}$ that do not bind to, or block receptor ligand-binding sites, their ligands, or receptor dimerization sites, but can be potent inhibitors of receptor TK-mediated signaling, has already been established in vitro [22] and validated in the clinic.

Major alterations in the PD- $\mu$ Constant Domain 4 $(\mu \mathrm{C} 4)$ juncture further differentiate sIgM and $\mathrm{mIgM}$ and provide additional neo-epitopes and functional capabilities for specific targeting. For example, the $\mu \mathrm{C} 4$ domain of $\mathrm{mIgM}$ is differentiated from $\operatorname{sgM} \mu \mathrm{C} 4$ by a 20 amino acid truncation, loss of the J-chain binding site, and loss of a glycosylation site, which taken together generate unique epitopes associated with a new functional site: an active mIgM clustering/signaling domain [23-27].

Here we present the biologic effects of novel antiPD mAbs. In contrast to the apoptotic effects observed in the anti-mIgE-PD system, only one of the anti-PDm mAbs significantly inhibited cell growth or induced apoptosis [28]. This mAb, with partial conformationdependent binding spanning the PDm- $\mu \mathrm{C} 4$ juncture, manifests receptor internalization, cell growth inhibition, anti-clonogenic activity [29], anti-stem-cell activity [30], and apoptosis in low-density cultures [31].

\section{RESULTS}

\section{Generation of hybridoma clones}

Because the mIgM PD peptide is relatively hydrophobic, generating high avidity mAbs required novel immunization strategies. Its 13-mer sequence is comprised of five hydrophobic amino acids V, A, F, and two Gs, in addition to amino acid $\mathrm{S}$ which has a relatively low hydrophobicity index. Thus, stabilizing these peptides with carrier immunogens was essential for immunization and in vitro screening assays. Given the hydrophobicity of the PDm sequence, it was initially unclear whether it was partially contained in the plasma membrane or was completely in the extracellular space and accessible for $\mathrm{mAb}$ binding.

With the goal of specifically modulating mIgM$\mathrm{CD} 79 \alpha / \beta$ signaling, mAbs targeting the PDm sequence and the contiguous proximal extra-cellular domain of the $\mathrm{mIgM}(\mu \mathrm{C} 4)$ were generated. Proprietary immunization techniques for hydrophobic peptide immunogens were employed. Panels of peptide-specific mAbs detecting the 13-mer peptide PDm sequence (EGEVSADEEGFEN), specific for $\mathrm{mIgM}$, and the 18-mer peptide PDg sequence (ELQLEESCAEAQDGELDG), specific for $\mathrm{mIgG}$, were generated first. Three candidate $\mathrm{mAbs}(\mathrm{mAb} 1, \mathrm{mAb} 2$, and $\mathrm{mAb3}$ ), detecting PDm, were selected for further testing. In these studies an anti-PDg mAb11.1 (mouse IgG1) served as both positive and negative isotype control $\mathrm{mAb}$ in specificity and biologic studies. The initial screening and clone selection which yielded $\mathrm{mAb} 1, \mathrm{mAb} 2$, and mAb3 was based on ELISA, Hemagglutination (HA), Western blots, and Scanning Immune Electron Microscopy (SEM) assays, all of which demonstrated binding to (1) PDm peptide, (2) $\mathrm{mIgM}$ cell lysate protein fractions, and (3) cultured mIgM+ expressing cell lines: CA 46 (CRL 1648), SU-DHL-5 (CRL 2958), Ramos (CRL 1596), Namalwa (CRL 1432), ST 486 (CRL 1647), MC 116 (CRL 1649), and HT (CRL 2260).

Using a high affinity anti-PDm mAb (mAb1), NP-40 cell lysates containing mIgM were immuneaffinity chromatography purified and used to immunize additional sets of mice. From these immunizations, second-generation mAbs detecting conformational BCRC epitopes, but not reacting with sIgM in ELISA assays and Western blots, were collected. One of these $\mathrm{mAbs}$, designated $\mathrm{mAb} 4$, is differentiated by manifesting additional biologic activities, such as inducing B-cell growth inhibition, as assessed by MTT technology applied to clonogenic limiting dilution assays [22]. This finding emphasizes the need to probe native proteins as a source of biologically active mAbs. These four mAbs, designated $\mathrm{mAb} 1, \mathrm{mAb} 2, \mathrm{mAb} 3$, and $\mathrm{mAb} 4$ (collectively referred to as the " $\mathrm{mAb}$ panel") were selected for further studies. 
Table 1A: Specificity Analysis of mAbs: ELISA assay of immunogen reactivity

\begin{tabular}{|c|c|c|c|c|c|c|c|c|c|}
\hline & & \multicolumn{8}{|c|}{ Antibody Probe } \\
\hline & $\begin{array}{l}\text { Molecular } \\
\text { Constructs- } \\
\text { Immunogens }\end{array}$ & mAb1 & $\mathbf{m A b 2}$ & $\mathbf{m A b 3}$ & mAb4 & $\begin{array}{l}\text { IgG1 isotype } \\
\text { control }\end{array}$ & $\begin{array}{c}\text { IgG2 isotype } \\
\text { control }\end{array}$ & $\begin{array}{c}\text { Anti-mIgG } \\
\text { mAb } 11\end{array}$ & $\begin{array}{l}\text { Anti-hu- } \\
\text { IgM }\end{array}$ \\
\hline 1 & $\mathrm{KLH}$ & 0.1 & 0.1 & 0.1 & 0.1 & 0.1 & 0.1 & 0.1 & 0.1 \\
\hline 2 & KLH-PDm & 4.0 & 4.0 & 4.0 & 0.5 & 0.1 & 0.1 & 0.1 & 0.1 \\
\hline 3 & KLH-PDg & 0.1 & 0.1 & 0.1 & 0.1 & 0.1 & 0.1 & 3.8 & 0.2 \\
\hline 4 & PDm-KLH & 4.0 & 4.0 & 4.0 & 0.9 & 0.1 & 0.1 & 0.1 & 0.1 \\
\hline 5 & PDg-KLH & 0.1 & 0.1 & 0.1 & 0.1 & 0.1 & 0.1 & 3.2 & 0.1 \\
\hline 6 & MAP & 0.2 & 0.2 & 0.2 & 0.1 & 0.1 & 0.1 & 0.1 & 0.1 \\
\hline 7 & MAP-PDm & 4.0 & 4.0 & 4.0 & 0.8 & 0.1 & 0.1 & 0.1 & 0.1 \\
\hline 8 & MAP-PDg & 0.2 & 0.1 & 0.1 & 0.1 & 0.1 & 0.1 & 3.5 & 0.2 \\
\hline 9 & PDm & 4.0 & 4.0 & 4.0 & 0.8 & 0.1 & 0.1 & 0.1 & 0.1 \\
\hline 10 & $\mathrm{PDg}$ & 0.2 & 0.1 & 0.1 & 0.1 & 0.1 & 0.1 & 3.3 & 0.1 \\
\hline 11 & P-F mIgM & 3.1 & 2.8 & 2.6 & 4.0 & 0.3 & 0.1 & 0.1 & 4.0 \\
\hline 12 & P-F + IA-mIgM & 3.3 & 2.5 & 2.3 & 4.0 & 0.1 & 0.2 & 0.1 & 4.0 \\
\hline 13 & PDm Isomer 1 & 3.8 & 3.2 & 3.0 & 0.9 & 0.1 & 0.1 & 0.1 & 0.1 \\
\hline 14 & PDm Isomer 2 & 3.2 & 3.0 & 3.2 & 0.7 & 0.1 & 0.1 & 0.1 & 0.2 \\
\hline
\end{tabular}

P-F - cell lysates prepared by Perfect FOCUS ${ }^{\mathrm{TM}}$, IA - immune affinity chromatography

Table 1B: Specificity Analysis of mAbs: Probing of Lymphatic and Non-Lymphatic cell lines by HA/ELISA

\begin{tabular}{|c|c|c|c|c|c|c|c|c|c|}
\hline & B-Cells & mAb1 & mAb2 & mAb3 & mAb4 & $\begin{array}{l}\text { IgG1 isotype } \\
\text { control }\end{array}$ & $\begin{array}{l}\text { IgG2 isotype } \\
\text { control }\end{array}$ & $\begin{array}{c}\text { Anti-mIgG } \\
\text { mAb11 }\end{array}$ & $\begin{array}{l}\text { Anti-hu- } \\
\text { IgM }\end{array}$ \\
\hline 1 & $\operatorname{IgM~k~(4)~}$ & $+/+$ & $+/+$ & $+/+$ & $+/+$ & $-/-$ & $-/-$ & $-/-$ & $+/+$ \\
\hline 2 & $\operatorname{IgM} 1(3)$ & $+/+$ & $+/+$ & $+/+$ & $+/+$ & $-/-$ & $-/-$ & $-/-$ & $+/+$ \\
\hline 3 & $\operatorname{IgG~k~(1)~}$ & $-/-$ & $-/-$ & $-/-$ & $-/-$ & $-/-$ & $-/-$ & $+/+$ & $-/-$ \\
\hline 4 & $\operatorname{IgG} 1(1)$ & $-/-$ & $-/-$ & $-/-$ & $-/-$ & $-/-$ & $-/-$ & $+/+$ & $-/-$ \\
\hline 5 & $\operatorname{IgE}(1)$ & $-/-$ & $-/-$ & $-/-$ & $-/-$ & $-/-$ & $-/-$ & $-/-$ & $-/-$ \\
\hline & $\begin{array}{c}\text { Non- } \\
\text { Lymphatic } \\
\text { Cell Lines }\end{array}$ & mAb1 & mAb2 & $\mathbf{m A b 3}$ & mAb4 & $\begin{array}{l}\text { IgG1 isotype } \\
\text { control }\end{array}$ & $\begin{array}{l}\text { IgG2 isotype } \\
\text { control }\end{array}$ & $\begin{array}{l}\text { Anti-mIgG } \\
\text { mAb11 }\end{array}$ & $\begin{array}{l}\text { Anti- } \\
\text { gpA33, } \\
\text { EpCa }\end{array}$ \\
\hline 6 & Colon (12) & $-/-$ & $-/-$ & $-/-$ & $-/-$ & $-/-$ & $-/-$ & $-/-$ & $+/+$ \\
\hline 7 & Breast (9) & $-/-$ & $-/-$ & $-/-$ & $-/-$ & $-/-$ & $-/-$ & $-/-$ & $+/+$ \\
\hline 8 & Lung (9) & $-/-$ & $-/-$ & $-/-$ & $-/-$ & $-/-$ & $-/-$ & $-/-$ & $+/+$ \\
\hline 9 & Melanoma (2) & $-/-$ & $-/-$ & $-/-$ & $-/-$ & $-/-$ & $-/-$ & $-/-$ & $-/-$ \\
\hline
\end{tabular}

The specific cell lines used are given in the Materials and Methods. Results indicate whether a particular assay gave a positive $(+)$ or negative (-) result in a modified HA assay and ELISA assay. (n) sample size

Table 1C: Specificity Analysis of mAbs: inhibition of ELISA by molecular constructs

\begin{tabular}{|c|c|c|c|c|c|c|c|c|c|}
\hline & Molecular Construct & mAb1 & mAb2 & mAb3 & mAb4 & $\begin{array}{l}\text { IgG1 isotype } \\
\text { control }\end{array}$ & $\begin{array}{c}\text { IgG2 } \\
\text { isotype } \\
\text { control }\end{array}$ & $\begin{array}{c}\text { Anti- } \\
\text { mIgG } \\
\text { mAb } 11\end{array}$ & $\begin{array}{c}\text { Anti-hu- } \\
\text { IgM }\end{array}$ \\
\hline 1 & $\mathrm{KLH}$ & 3.9 & 3.5 & 3.6 & 3.8 & 0.1 & 0.1 & 0.1 & 3.9 \\
\hline 2 & KLH-PDm & 0.7 & 0.3 & 0.4 & 3.8 & 0.1 & 0.1 & 0.2 & 3.9 \\
\hline 3 & KLH-PDg & 4.0 & 3.6 & 3.7 & 4.0 & 0.1 & 0.1 & 0.1 & 3.8 \\
\hline 4 & $\mathrm{PDm}$ & 0.4 & 0.5 & 0.4 & 3.8 & 0.1 & 0.1 & 0.2 & 3.9 \\
\hline 5 & $\mathrm{PDg}$ & 4.0 & 3.8 & 3.2 & 3.9 & 0.1 & 0.1 & 0.3 & 3.7 \\
\hline 6 & P-F mIgM & 0.2 & 0.3 & 0.3 & 0.2 & 0.1 & 0.1 & 0.2 & 0.2 \\
\hline 7 & $\mathrm{P}-\mathrm{F}+\mathrm{IA}$ mIgM & 0.3 & 0.4 & 0.2 & 0.2 & 0.1 & 0.1 & 0.2 & 0.2 \\
\hline
\end{tabular}

P-F - cell lysates prepared by Perfect FOCUS ${ }^{\mathrm{TM}}$ technology, IA - immune affinity chromatography 
Table 1D: Specificity Analysis of mAbs: ELISA assay of biological (serum) samples

\begin{tabular}{|c|c|c|c|c|c|c|c|c|c|}
\hline & Biologic Specimens & mAb1 & mAb2 & mAb3 & mAb4 & $\begin{array}{c}\text { IgG1 } \\
\text { isotype } \\
\text { control }\end{array}$ & $\begin{array}{c}\text { IgG2 } \\
\text { isotype } \\
\text { control }\end{array}$ & $\begin{array}{c}\text { Anti-mIgG } \\
\text { mAb11 }\end{array}$ & $\begin{array}{c}\text { Anti-hu- } \\
\text { IgM }\end{array}$ \\
\hline $\mathbf{1}$ & Normal serum (6) & $\mathbf{0 . 2}$ & $\mathbf{0 . 2}$ & $\mathbf{0 . 3}$ & $\mathbf{0 . 3}$ & $\mathbf{0 . 2}$ & $\mathbf{0 . 3}$ & $\mathbf{0 . 4}$ & $\mathbf{4 . 0}$ \\
\hline $\mathbf{2}$ & Purified IgM (1) & $\mathbf{0 . 3}$ & $\mathbf{0 . 4}$ & $\mathbf{0 . 3}$ & $\mathbf{0 . 3}$ & $\mathbf{0 . 3}$ & $\mathbf{0 . 2}$ & $\mathbf{0 . 2}$ & $\mathbf{4 . 0}$ \\
\hline $\mathbf{3}$ & W-M serum (2) & $\mathbf{0 . 3}$ & $\mathbf{0 3}$ & $\mathbf{0 . 3}$ & $\mathbf{0 . 2}$ & $\mathbf{0 . 2}$ & $\mathbf{0 . 2}$ & $\mathbf{0 . 3}$ & $\mathbf{4 . 0}$ \\
\hline
\end{tabular}

(n) - sample size, W-M - Waldenstrom macroglobulinemia

Table 1E: Specificity Analysis of mAbs: inhibition of ELISA by biological constructs

\begin{tabular}{|c|c|c|c|c|c|c|c|c|c|}
\hline & Biological Construct & $\mathbf{m A b 1}$ & mAb2 & mAb3 & mAb4 & $\begin{array}{c}\text { IgG1 } \\
\text { isotype } \\
\text { control }\end{array}$ & $\begin{array}{l}\text { IgG2 } \\
\text { isotype } \\
\text { control }\end{array}$ & $\begin{array}{c}\text { Anti- } \\
\text { mIgG } \\
\text { mAb } 11\end{array}$ & $\begin{array}{c}\text { Anti-hu- } \\
\text { IgM }\end{array}$ \\
\hline 1 & Normal serum (3) & 3.9 & 3.7 & 3.9 & 4.0 & 0.1 & 0.1 & 0.2 & 0.2 \\
\hline 2 & Normal plasma (3) & 3.7 & 3.8 & 3.7 & 3.9 & 0.1 & 0.1 & 0.1 & 0.4 \\
\hline 3 & $\mathrm{~W}-\mathrm{M}$ serum (2) & 3.8 & 3.8 & 3.8 & 4.0 & 0.1 & 0.2 & 0.1 & 0.1 \\
\hline 4 & DLBCL serum (3) & 3.5 & 3.6 & 3.7 & 4.0 & 0.1 & 0.1 & 0.1 & 0.8 \\
\hline 5 & NHL serum (3) & 3.4 & 3.3 & 3.7 & 3.9 & 0.1 & 0.1 & 0.2 & 0.7 \\
\hline 6 & Breast Ca serum (3) & 3.6 & 3.7 & 3.6 & 4.0 & 0.1 & 0.1 & 0.2 & 0.3 \\
\hline 7 & Colon Ca serum (3) & 3.8 & 3.4 & 3.8 & 4.0 & 0.1 & 0.1 & 0.1 & 0.3 \\
\hline 8 & CLL serum (3) & 3.8 & 3.7 & 3.8 & 4.0 & 0.1 & 0.1 & 0.2 & 1.9 \\
\hline 9 & CLL cells (3) & 0.2 & 0.2 & 0.1 & 0.1 & 0.1 & 0.1 & 0.2 & 0.6 \\
\hline
\end{tabular}

(n) sample size

\section{Specificity analyses}

Serial assays testing each hybridoma clone's specificity were used to select and further characterize the clinical candidates comprising the final $\mathrm{mAb}$ panel. In all specificity assays (Table 1A-1E), isotype-matched IgG1 and $\mathrm{IgG} 2$ antibodies (Abs) served as negative controls and anti-mIgG and anti-huIgM served as positive controls for the specified substrate (four columns on the right hand side of the tables). The first set of screens employed plates coated with molecular constructs consisting of (1) carrier alone, (2) peptides alone, (3) carrier with $\mathrm{C}$ - or N-terminal conjugation and peptides, (4) purified membrane fractions, and (5) two isomers of the PDm (Table 1A). As expected those constructs that lacked the PDm sequence were negative (Table 1A: Rows 1, 3, 5, 6, 8, 10) while those that contained PDm were positive (Table 1A: Rows 2, 4, 7, 9, 11, 12). Table 1A (Rows 13 and 14) shows PDm peptides with a $\mathrm{V}$ to $\mathrm{N}$ amino acid substitution at position 4 (Isomer 1) and an A to E substitution at position 6 (Isomer 2). mAb4 was the only one of the four mAbs to be significantly affected by these changes suggesting that it is sterically inhibited.

To determine whether the mAbs are capable of binding to the specific PDm sequence in the native state, and to eliminate the possibility of artifactual, non-specific, low-affinity hydrophobic binding, a modified HA assay of intact cells (see Materials and Methods) and ELISA assays using cell lysates were performed. The results are scored as either positive $(+)$ or negative $(-)$ and both lymphatic and non-lymphatic cells lines were tested in the HA and cell lysate assays. A portion of these cell lines were prescreened by RT-PCR to confirm mIgM expression. The results show that each of the mAbs recognizes cells or their lysates from only those cells containing the PDm, confirming their specificity for the native target (Table 1B: Rows 1 and 2). Negative control mIgG- and mIgEexpressing cells (Table 1B: Rows 3-5), as well as all of the Non-Lymphatic cell lines (Table 1B: Rows 6-9), were negative in both assays. We found that all cell lines expressing IgM by RT-PCR were also positive for $\mathrm{mIgM}$ by Western blot (data not shown). In some cell lines, mIgM expression was very low, $<10,000$ receptors per cell as determined from SEM estimates (e.g. CRL 1648; Figure 1A-1C). Furthermore, reactivity with our panel of anti-PD mAbs suggested that when $\mathrm{mIgM}$ was detectable in cell lysates (ELISA assays), it was also present on the cell surface (HA assays) (Table 1B), correlating cell protein expression with cell surface expression.

Investigations with SEM also confirmed the cell-surface localization of the mIgM on intact viable target cells (Figure 1A-1C). Taken together, as cell lines were found to express mIgM in HA assays, cell 
lysate ELISA assays, SEM, and mIgM RT-PCR, these results suggest a strong correlation between mRNA expression, mIgM protein synthesis, and cell surface expression. These results are also in agreement with ATCC cell line mIgM expression data. In addition, HA/ ELISA data indicated that the four mAbs do not crossreact nor detect any determinants on the surface of the non-mIgM expressing B-cell lines or the epithelial/non- lymphatic cell lines tested $(p<0.05)$ (Table 1B). Thus, these assays demonstrate both the restricted nature of mIgM expression, and lack of cross-reactive determinants in a variety of non-B-cell lineages. Therefore, the PDm sequence is not detected by immunologic means in nonmIgM-expressing cells. Isotype-matched control mouse $\mathrm{mAbs}$, and anti-epithelial Abs were negative for B-cell lines, ruling out non-specific Fc receptor binding (Table
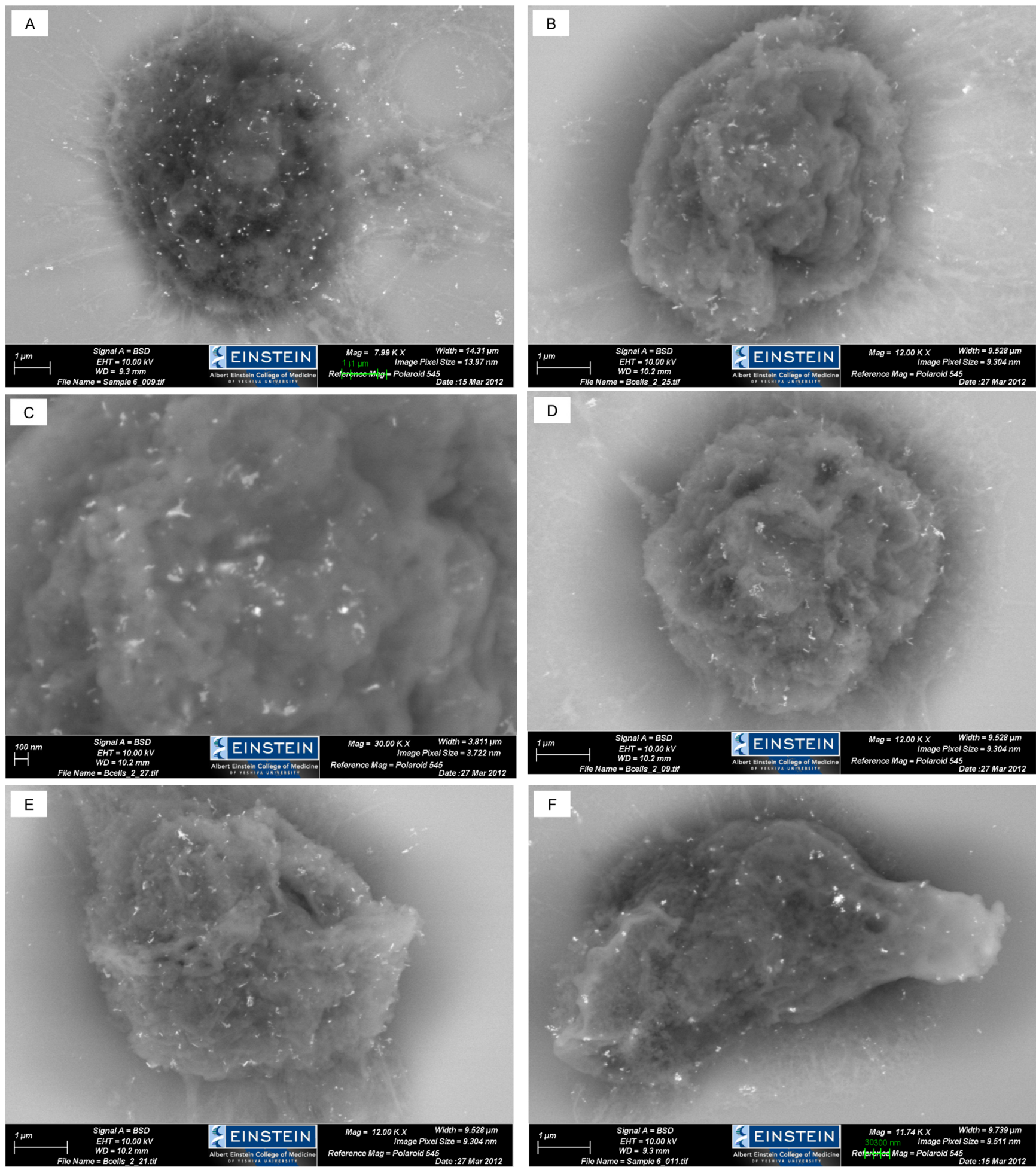

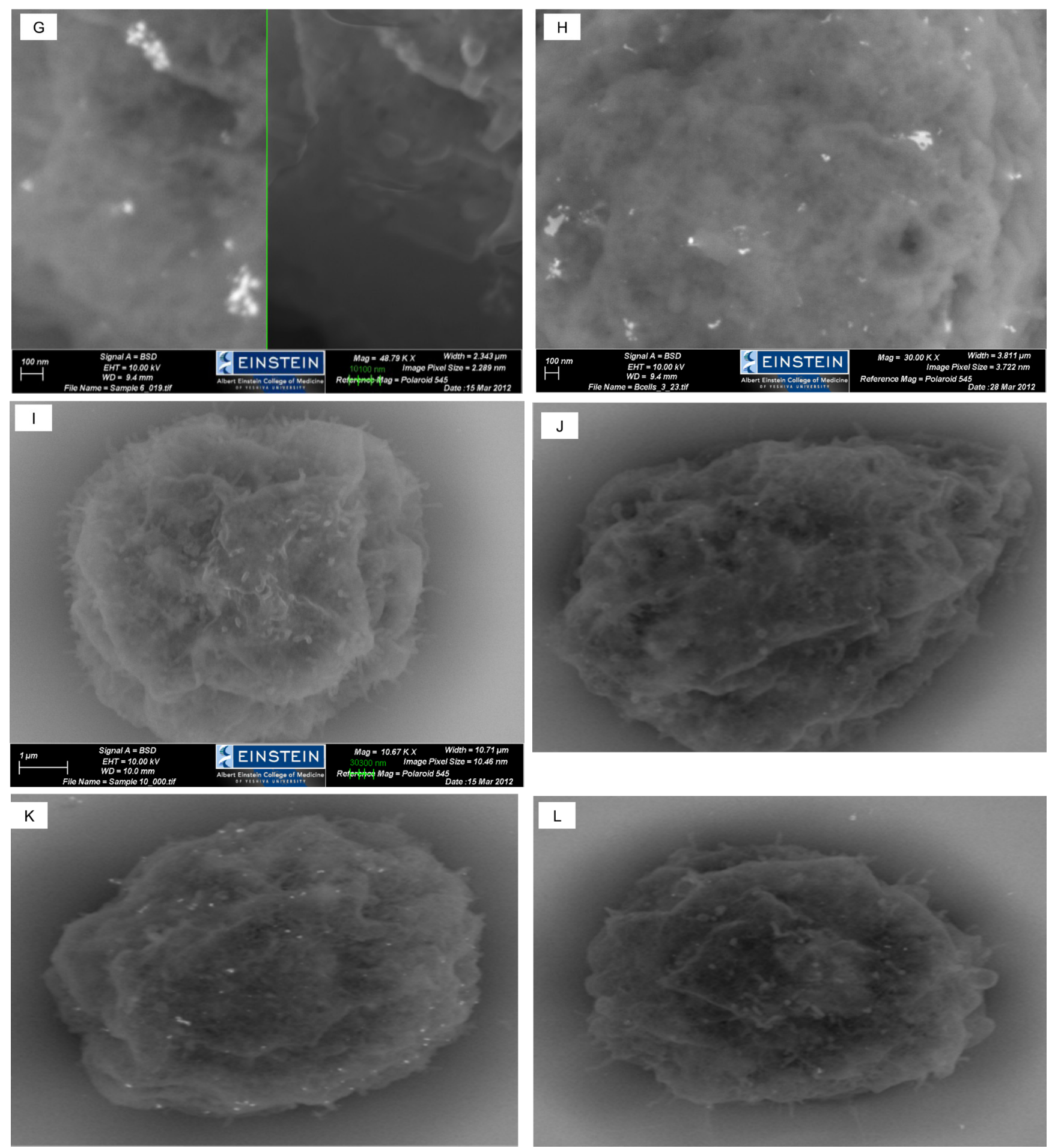

Figure 1: SEM of mAb binding to cell surfaces. A., B., and C. show mAb4 binding to CRL 1648 cells. Anti-PD mAb1 D., mAb2 E., and $\mathrm{mAb} 3 \mathbf{F}$. bind to CRL 1648. Isotype control $\mathrm{mAb}$ (IgG1) binding to CRL 1648 is shown in J. Various degrees of micro-clustering are identified in most cells examined, shown for mAb4 G. and mAb1 H. Polyclonal mouse anti-huIgM cell reactivity post mAb4-induced receptor internalization I.. Kinetics of mAb4 internalization at $5 \mathbf{K}$. or $30 \mathrm{mins}$ L. post incubation, compared to glutaraldehyde-fixed cells exposed to mAb4 (A, B, and C) or control $\mathrm{mAb} \mathbf{J}$.

1B). Control positive and negative anti-mIgG, mAb11.1, and a control positive polyclonal goat anti-huIgM reagent demonstrated the specificity and robustness of the assay ( $p$
$<0.05$ ) (Table 1B). Flow cytometry experiments detected $\mathrm{mIgM}$ as a "DIM" signal, due to low mIgM expression levels. Thus, this technology was considered inadequate 
Table 2: Molecular Epitope Mapping by Competitive mAb Binding

\begin{tabular}{|l|c|c|c|c|c|}
\hline \multicolumn{1}{|c|}{ Blocked by mAb1 } & mAb1 & mAb2 & mAb3 & mAb4 & Control mAb \\
\hline mIgM-PD & 11 & 88 & 82 & 72 & neg \\
\hline mIgG-PD & $n e g$ & neg & neg & neg & neg \\
\hline KLH-mIgM-PD & 6 & 94 & 92 & 74 & neg \\
\hline mIgM-PD-KLH & 10 & 92 & 91 & 52 & neg \\
\hline P-Focus + IA & 13 & 90 & 89 & 96 & neg \\
\hline Blocked by mAb 2 & mAb1 & mAb2 & mAb3 & mAb4 & Control mAb \\
\hline mIgM-PD & 80 & 2 & 23 & 69 & neg \\
\hline mIgG-PD & neg & neg & neg & neg & neg \\
\hline KLH-mIgM-PD & 67 & 4 & 24 & 68 & neg \\
\hline mIgM-PD-KLH & 78 & 2 & 34 & 71 & neg \\
\hline P-Focus + IA & 78 & 3 & 31 & 96 & neg \\
\hline Blocked by mAb 3 & mAb1 & mAb2 & mAb3 & mAb4 & Control mAb \\
\hline mIgM-PD & 85 & 35 & 9 & 63 & neg \\
\hline mIgG-PD & neg & neg & neg & neg & neg \\
\hline KLH-mIgM-PD & 79 & 28 & 4 & 72 & neg \\
\hline mIgM-PD-KLH & 87 & 36 & 9 & 62 & neg \\
\hline P-Focus +IA & 82 & 39 & 10 & 85 & neg \\
\hline Blocked by mAb 4 & mAb1 & mAb2 & mAb3 & mAb4 & Control mAb \\
\hline mIgM-PD & 93 & 87 & 84 & 12 & neg \\
\hline mIgG-PD & neg & neg & neg & neg & neg \\
\hline KLH-mIgM-PD & 82 & 88 & 95 & 14 & neg \\
\hline mIgM-PD-KLH & 90 & 94 & 85 & 9 & neg \\
\hline P-Focus + IA & 94 & 86 & 9 & neg \\
\hline
\end{tabular}

for experiments examining mIgM cell surface expression and experiments measuring the reduction in signal due to antigen internalization (data not shown).

HA was originally designed as a methodology to rapidly assess $\mathrm{Ab}$ cell-surface binding to adherent target cells, and was adapted here for non-adherent or weakly-adherent cells (see Materials and Methods: Hemadsorption/Hemagglutinin assays). Using diluted test samples, this assay became especially sensitive in detecting non-rosetted cells. Thus, it was useful in confirming that virtually all cells within the positive cell lines were HA positive, and heterogeneity of mIgM expression, for positive and negative cells, was not detectable with any of the four mAbs tested and in any of the cell lines tested (Table 1B). The protein G-RBC also weakly detected IgG-expressing B-cells even without the addition of $\mathrm{mAb}$, indicating its weak binding to surfaceexpressed $\mathrm{mIgG}$. As this binding was blocked by preincubation of protein G-RBCs with control IgG2a, it indicates that the protein G-RBC HA reaction is mediated by the protein G-Ig binding. In these $\mathrm{mIgG}$-expressing cells, HA background was as high as $30 \%$.

ELISA assays testing the reactivity of the mAbs to the immunogen molecular constructs (bound to solid phase) further demonstrate the restrictive reactivity of the four mAbs in our panel. No reactivity was observed with carrier proteins keyhole limpet hemocyanin (KLH) or multiple antigen peptide (MAP), or with PDg when bound to KLH, MAP, or used without carrier. Observed reactivity was restricted to free or conjugated $\operatorname{PDm}(p<$ 0.05) (Table 1A).

A critical finding shown here is the relatively enhanced reactivity of $\mathrm{mAb} 4$ to purified native $\mathrm{mIgM}$ (Table 1A: Rows 11, 12) compared to its binding to PDm-containing structures (Table 1A: Rows 2, 4, 7, 9) particularly when compared to $\mathrm{mAb} 1, \mathrm{mAb} 2$, and $\mathrm{mAb} 3$ binding patterns. Both the Perfect FOCUS ${ }^{\mathrm{TM}}$ lysate fraction, and the same fraction further enriched for $\mathrm{mIgM}$ by mAb1-Immune-affinity chromatography (Perfect FOCUS $^{\text {TM }}+$ IA), showed preferred mAb4 binding ( $p<$ $0.05)$. These findings suggest that $\mathrm{mAb} 4$ has preferential binding to the intact native $\mathrm{mIgM}$ protein when compared to the PDm peptide and that its epitope may reside predominantly in the $\mu \mathrm{C} 4$ domain or may depend on this structure for proper conformation.

The two isomeric forms of the PDm (Table 1A: Rows 13,14$)$ appear to be detected by each of the mAbs with the same relative reactivity as the immunizing PDm 
Table 3: Molecular Epitope Mapping by Competitive 6-mer Peptide Binding

\begin{tabular}{|l|c|c|c|c|c|}
\hline \multicolumn{7}{|c|}{ Blocked by 6-mer A } \\
\hline Solid Phase Target & mAb1 & mAb2 & mAb3 & mAb4 & Control mAb \\
\hline mIgM-PD & 28 & 45 & 61 & 81 & neg \\
\hline mIgG-PD & neg & neg & neg & neg & neg \\
\hline P-Focus & 19 & 53 & 54 & 90 & neg \\
\hline \multicolumn{7}{|c|}{ Blocked by 6-mer B } \\
\hline Solid Phase Target & mAb1 & mAb2 & mAb3 & mAb4 & Control mAb \\
\hline mIgM-PD & 84 & 57 & 50 & 70 & neg \\
\hline mIgG-PD & neg & neg & neg & neg & neg \\
\hline P-Focus & 90 & 48 & 57 & 94 & neg \\
\hline
\end{tabular}

or Perfect FOCUS ${ }^{\mathrm{TM}}$ purified mIgM fraction $(p<0.05)$. These isomeric forms have a single amino acid variant each, substituting $\mathrm{N}$ for $\mathrm{V}$ and $\mathrm{E}$ for $\mathrm{A}$ at positions 4 and 6 in the 13-mer PDm, rendering these forms more hydrophilic than the most common isomer used in this study for immunization. These mAbs therefore cannot be used to distinguish the different $\mathrm{mIgM}$ isomeric forms and further investigations are needed to determine their biologic differences

The positive control goat anti-huIgM reagent is not reactive with PDm or its conjugated structures, but does recognize the mIgM-purified samples $(p<0.05)$ (Tables $1 \mathrm{~A}-1 \mathrm{E})$. This indicates that common commercial human IgM preparations, used for immunizations to generate anti-huIgM research reagents, do not contain the PDm sequence or PDm is too weak in this context to induce an immune response. To further confirm the direct $\mathrm{mAb}$ binding ELISA assay (Table 1A), more sensitive inhibition of ELISA mAb binding assays are shown in Table 1C, confirming the highly selective specificity of these Abs.

To determine if, in vivo, mIgM-containing immunogenic PDm or $\mu \mathrm{C} 4$ are secreted or released from live cells by enzymatic means or by an apoptotic process, normal human serum, purified hu-IgM, and serum from Waldenstrom's Macroglobulinemia patients were each tested, bound to solid phase in ELISA assays, and found to be non-reactive with the mAb panel $(p<0.05)$ (Table 1D). To confirm these results, higher sensitivity inhibition assays were conducted using the same sera samples, now pre-incubated in antigen excess with the mAbs prior to use in ELISA assays, such as the direct binding to the Perfect-FOCUS ${ }^{\mathrm{TM}}$ purified mIgM fraction (Table 1E). These inhibitory assays confirmed the results of the direct binding assays $(p<0.05)$. Following these initial experiments, an expanded panel of sera from normal patients, and a variety of patients with lymphatic and nonlymphatic malignancies, were tested, and demonstrated a lack of circulating $\mathrm{mIgM}$ in serum. In contrast, fresh frozen CLL cells ( $1 \times 10^{6}$ cells in DMSO) almost completely absorbed each of the mAbs $(1 \mu \mathrm{g} / \mathrm{ml})$, and thus reduced $\mathrm{mAb}$ binding in direct binding assays to the Perfect-FOCUS ${ }^{\mathrm{TM}}$ purified mIgM fraction $(p<0.05)$
(Table 1E). These fresh frozen CLL purified mononuclear cells separated by Ficoll-Hypaque technology were a source for NP-40 lysates and Perfect FOCUS ${ }^{\mathrm{TM}}$ fractions for immune-affinity chromatography, immunizations, and ELISA assays.

SEM was used to investigate the cell binding patterns of the panel of mAbs to B-cell lines and to confirm the results of the HA and ELISA assays. The cell surface spatial array of mIgM receptor is poorly understood with regards to polymerization of $\mathrm{mIgM}$ by the $\mu \mathrm{C} 4$ clustering-domain, and to non-covalent CD79 $\alpha / \beta$ complexing. We explored whether the PDm or $\mu \mathrm{C} 4$ clustering-domain is actively complexed on the cell surface and whether the mAb epitopes can still be detected in the presence of $\mathrm{mIgM}$ clustering. Except for PDm, class-specific PDs contain cysteines, which are hypothesized to be responsible for cross-linking mIg. mAbs detecting these PDs need to recognize the crosslinked PD. In the absence of cysteines in PDm, whether the hydrophobic nature of the PDm mediates its crosslinking is not supported by experimental data [25-27]. For this reason, SEM was carried out to provide additional evidence of mAbs binding to the cell surface of mIgMexpressing cells (Figure 1A-1F) but not to non-expressors. At higher magnification, "small" micro-clusters of mIgM were visualized by the gold-labeled goat anti-mouse Ig reagent (Figure 1G, 1H). As these "small" micro-clusters were visualized in glutaraldehyde-fixed cells, they are not a consequence of $\mathrm{mAb}$-induced clustering, but rather represent de novo clustered mIgM. Similar complexes have been identified in diffuse large B-cell lymphoma cell lines (DLBCL); however, it is unclear whether they correspond to the micro-clustering previously described in DLBCL samples [25-27]. The two DLBCL cell lines both demonstrated large clusters likely representing the previously described micro-clustering [25-27]. The cell line CRL 1648 represents a B-cell line with relatively low mIgM expression based on "DIM" light chain reactivity by flow cytometric analysis, similar to CLL cells, and is shown in Figure 1A-1C. This cell line is not thought to be derived from a DLBCL patient. Similar "small' micro-clusters were found in all the B-cell lines examined 
Table 4: Detection of mAb-Induced mIgM Internalization by Adsorption: binding of mAb4-HRP after adsorption with pre-treated cells washed with PBS or acetate

\begin{tabular}{|c|c|c|c|c|}
\hline $\begin{array}{c}\text { Cell treatment prior to } \\
\text { exposure to mAb4 }\end{array}$ & $\begin{array}{c}\text { Cell treatment after } \\
\text { exposure to mAb4, but } \\
\text { prior to adsorption of } \\
\text { mAb4-HRP }\end{array}$ & $\begin{array}{c}\text { CRL 1648 \% } \\
\text { binding of } \\
\text { adsorbed mAb4- } \\
\text { HRP to P-F mIgM }\end{array}$ & $\begin{array}{c}\text { CRL 1647 \% } \\
\text { binding of } \\
\text { adsorbed mAb4- } \\
\text { HRP to P-F IgM }\end{array}$ & $\begin{array}{c}\text { CRL 1596 \% } \\
\text { binding of adsorbed } \\
\text { mAb4-HRP to P-F } \\
\text { IgM }\end{array}$ \\
\hline Glutaraldehyde-Fixed & PBS & 100 & 100 & 100 \\
\hline Glutaraldehyde-Fixed & Acetate & 10 & 21 & 19 \\
\hline Live cells on Ice & PBS & 92 & 95 & 88 \\
\hline Live cells on Ice & Acetate & 12 & 18 & 20 \\
\hline Live, $37^{\circ} \mathrm{C}(5 \mathrm{~min})$ & PBS & 77 & 67 & 66 \\
\hline Live, $37^{\circ} \mathrm{C}(5 \mathrm{~min})$ & Acetate & 26 & 81 & 27 \\
\hline Live, $37^{\circ} \mathrm{C}(15 \mathrm{~min})$ & PBS & 78 & 44 & 72 \\
\hline Live, $37^{\circ} \mathrm{C}(15 \mathrm{~min})$ & Acetate & 48 & 64 & 66 \\
\hline Live, $37^{\circ} \mathrm{C}(30 \mathrm{~min})$ & PBS & 70 & 62 & 60 \\
\hline Live, $37^{\circ} \mathrm{C}(30 \mathrm{~min})$ & Acetate & 66 & 6 \\
\hline
\end{tabular}

regardless of their proposed original tissue diagnosis. These results demonstrate the accessibility of each mAb to their respective epitope in the mIgM clustered state.

\section{Fine molecular epitope mapping by competitive $\mathrm{mAb}$ binding and peptide inhibition}

Epitope binding for each of the mAbs was determined using four complimentary assays, 1) $\mathrm{mAb}$ blocking of horseradish peroxidase (HRP)-labeled mAb binding to antigen in ELISA assays, 2) specific peptide inhibition of HRP-labeled $\mathrm{mAb}$ binding to antigen in ELISA assays, 3) specific peptide inhibition of $\mathrm{mAb}$ cell surface binding to target cells as determined by SEM, and 4) $\mathrm{mAb}$ cell surface binding to target cells as determined by SEM using isotype specific probes.

Protein labeling techniques for direct HRP conjugation to $\mathrm{mAb}$ allowed for testing of inhibition of $\mathrm{mAb}$-HRP binding in solid-phase ELISA assays. By using excess unlabeled $\mathrm{mAb}$ to block labeled $\mathrm{mAb}-\mathrm{HRP}$ binding (Table 2), the following groups of clones were defined: those blocking the labeled $\mathrm{mAb}$ (same epitope), those not blocking the labeled mAb (different epitope), and those partially blocking the labeled $\mathrm{mAb}$ (a near epitope or weaker binding). In separate experiments each $\mathrm{mAb}$ was labeled with HRP and the inhibitory unlabeled blocking $\mathrm{mAb}$ assay was repeated until all the clones were epitope defined. mAb1 did not block mAb2, mAb3, or mAb4, but is self-blocked by unlabeled mAb1 $(p<0.05)$; mAb2 did not block mAb1 or mAb4, but did partially block mAb3, and unlabeled mAb2 blocked itself $(p<0.05)$. These results were similar for $\mathrm{mAb} 3$ analysis showing partial blocking by excess mAb2 $(p<0.05)$. mAb4 demonstrated lack of blocking by mAb1, mAb2, and mAb3 but blocked itself $(p<0.05)$. The results suggest that for PDm, KLHPDm, and Perfect FOCUS ${ }^{\mathrm{TM}}+$ IA chromatography fraction, $\mathrm{mAb} 1$ and $\mathrm{mAb} 4$ each detected a distinct epitope while $\mathrm{mAb} 2$ and $\mathrm{mAb} 3$ detected another defined epitope that is partially shared. mAb4, while binding to PDm, showed relatively improved binding to purified $\mathrm{mIgM}$ (Perfect FOCUS $\left.{ }^{\mathrm{TM}}+\mathrm{IA}\right)$ vs. PDm $(p<0.05)$, especially when compared to the patterns of reactivity of the other $\mathrm{mAbs}$, again suggesting preferential binding to a naturally derived-PDm epitope or a conformational dependency provided by $\mu \mathrm{C} 4$.

Inhibition assays, testing 6-mer peptides for their ability to block the mAbs binding to peptide or the Perfect FOCUS ${ }^{\mathrm{TM}}+$ IA purified fraction in solid-phase ELISA assays, were conducted to confirm the data from the $\mathrm{mAb}$ epitope mapping studies, and to more precisely define the target epitopes (Table 3). The 6-mer A-peptide (EGEVSA) and 6-mer B-peptide (EEGFEN) were used in molar excess (X100) compared to the mAb-HRP. These studies demonstrated that $\mathrm{mAb} 4$ detected a distinct epitope not substantially blocked by either the 6-mer A-peptide or B-peptide. While mAb1 was not blocked by the 6-mer B-peptide, mAb1 was strongly blocked by the 6-mer A-peptide $(p<0.05)$, and $\mathrm{mAb} 2$ and $\mathrm{mAb} 3$ were partially blocked by both 6-mer A-peptide and B-peptide $(p<$ $0.05)$. It should be noted that the high level of hydrophobic amino acids in A-peptide: G, V, and A, and in B-peptide: $\mathrm{G}$, and F; may affect results of this assay due to solubility characteristics. Thus, the partial blocking of mAb2 and mAb3 by the 6-mers may represent relative avidity or solubility issues. Taking these uncertainties together prevents clear epitope target designations for $\mathrm{mAb} 2$ and $\mathrm{mAb3}$. mAb1 is blocked by the most hydrophobic sequences, emphasizing the unusual nature of this $\mathrm{Ab}$. For this reason, we show the SEM demonstrating its cell 
binding in Figure 1D.

In an effort to better assign a specific epitope target for these mAbs, additional studies were carried out using a 15-mer peptide, extending the 13-mer PDm into the $\mu \mathrm{C} 4$ domain. These studies indicated that $\mathrm{mAb} 4$ had a modest $(<10 \%)$, but statistically insignificant increase in binding to the extended 15-mer compared to the 13-mer ( $p>0.05)$, while there was no change in mAb2 and mAb3 binding. In addition, the 15-mer had low, non-significant blocking activity in mAb4 binding to the Perfect FOCUS ${ }^{\mathrm{TM}}+$ IA purified fraction (data not shown). These data again suggest that mAb4 binds only weakly to the PDm, and more robustly to a proximal $\mu \mathrm{C} 4$ epitope not contained in the 15 -mer, or that its epitope is partially conformational and it is not represented well in linear hydrophobic peptides, which may have alternative folding patterns.

SEM studies were used to confirm results of the ELISA blocking experiments. The binding of mAbs to glutaraldehye-fixed CRL 1648 cells was determined by SEM after incubation of the mAbs with excess PDm peptide or 6-mers (x500). mAb1, mAb2, and mAb3 binding to the cell surface of CRL 1648 was blocked by PDm peptide or their respective 6-mer, as seen by SEM testing, whereas mAb4 was not fully blocked, and binding to the CR-1648 cell surface, while reduced, was readily detected (data not shown).

To further examine the mAb4 epitope, SEM studies were carried out on fixed CRL 1648 cells incubated with $\mathrm{mAb} 1$. Isotype specific goat anti-mouse IgG1 gold-labeled reagent did not detect the bound IgG2b mAb1, but when the IgG1 mAb4 was subsequently added it was able to detect bound $\mathrm{mAb} 4$. The anti-mouse IgG1-gold reagent complex detected IgG1 mAb4, bound to the surface of glutaraldehyde-fixed CRL 1648 cells, pre-incubated with the IgG2b mAb2, indicating that $\mathrm{mAb} 2$ binds to a different epitope than mAb4 and does not block mAb4 cell binding (data not shown).

\section{mAb-induced receptor internalization}

When viable cells were examined, initial SEM studies indicated that detection of cell surface bound $\mathrm{mAb}$ or mouse anti-huIgM sera was both time and temperature dependent. Incubation of $\mathrm{mAb}$ or polyclonal mouse anti-huIgM sera at $4{ }^{\circ} \mathrm{C}$ for 30 mins was compared to incubation at $37{ }^{\circ} \mathrm{C}$ for 30 mins. At $37^{\circ} \mathrm{C}$, neither $\mathrm{mAb}$ nor mouse anti-huIgM reagent was detectable, but if incubated at $4{ }^{\circ} \mathrm{C}$, cell surface bound $\mathrm{mAb}$ and mouse antihuIgM was detectable. These findings were interpreted as $\mathrm{Ab}$ modulation of receptor $\mathrm{mIgM}$ expression, being consistent with $\mathrm{Ab}$-induced receptor internalization, a metabolic process that is reduced at $4{ }^{\circ} \mathrm{C}$. Fixation with glutaraldehyde was also demonstrated to stop this biologic
A

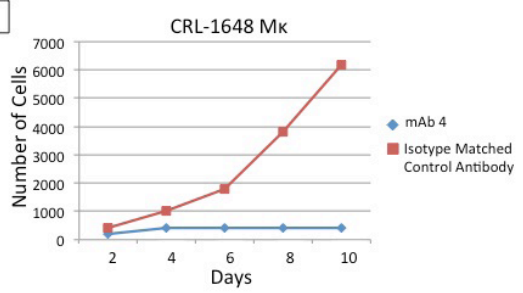

B

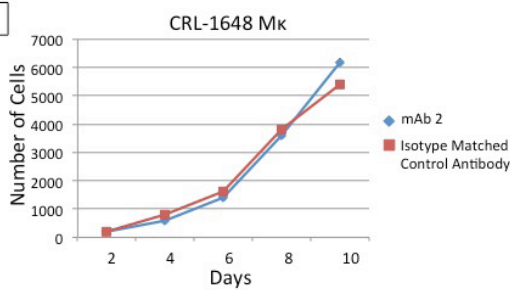

G

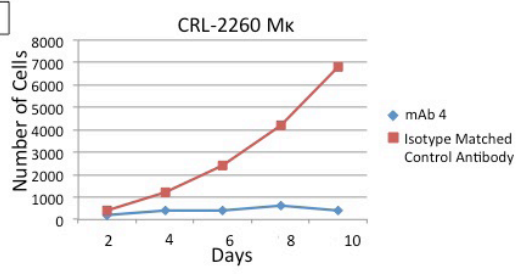

C

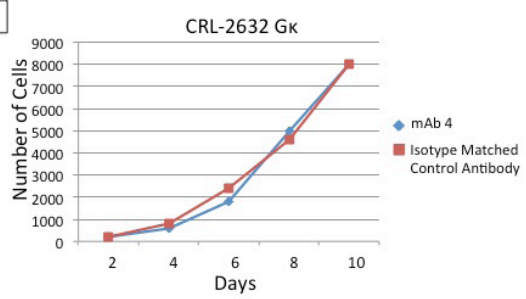

D

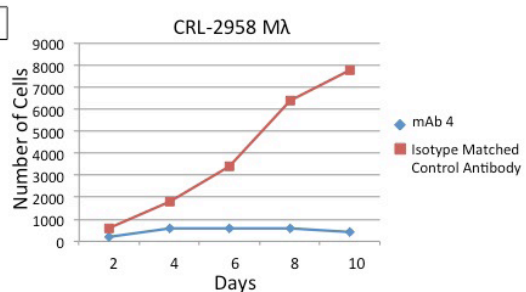

H

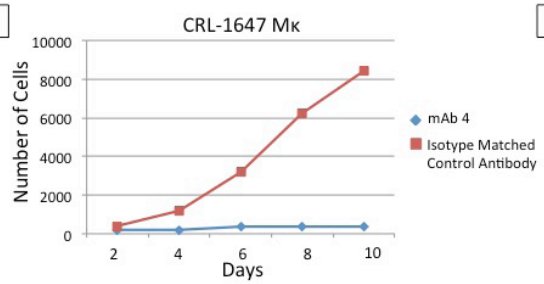

E

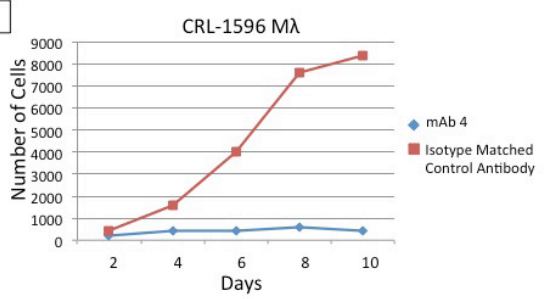

F

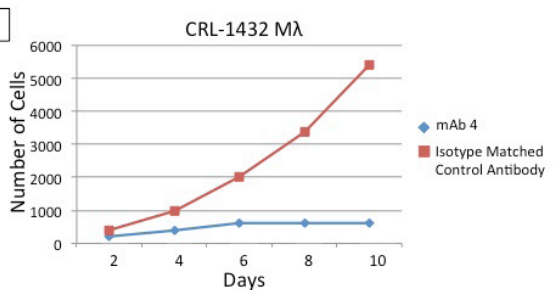

1

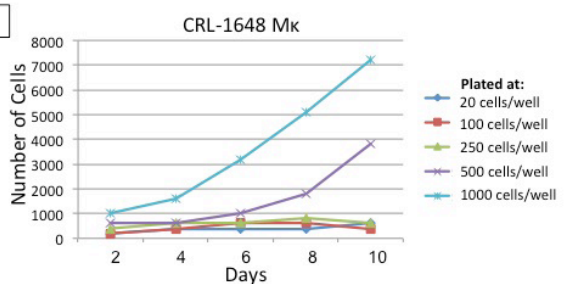

Figure 2: mAb4 inhibition of B-cell line growth. A.-H. Blue curves represent number of cells of a cell line, specified in chart titles, cultured in the presences of $1 \mu \mathrm{g} / \mathrm{ml}$ of $\mathrm{mAb} 4$ or $\mathrm{mAb} 2$, as indicated, from two to ten days. Red curves represent the number of cells of these cell lines cultured in the presence of isotype-matched control IgG1. I. Number of viable cells (estimated from MTT optical density (OD)) across two to ten days in limiting dilutions assays with between 20 and 1,000 cells plated per well. 
Table 5: mAb4-Mediated Growth Inhibition in Limiting Dilution Assays Assessed by Well Size

\begin{tabular}{|c|c|c|c|c|c|c|}
\hline Cell Lines & 10 cells $/ 0.3 \mathrm{~cm}^{2}$ & 10 cells $/ 0.7$ cm $^{2}$ & 10 cells $/ 2.0 \mathrm{~cm}^{2}$ & 50 cells/ $0.3 \mathrm{~cm}^{2}$ & 50 cells/ $0.7 \mathrm{~cm}^{2}$ & 50 cells $/ 2.0 \mathrm{~cm}^{2}$ \\
\hline CRL 1648 & 32 & 21 & $<1$ & 67 & 25 & $<1$ \\
\hline CRL 1647 & 41 & 18 & $<1$ & 57 & 28 & $<1$ \\
\hline CRL 1596 & 36 & 23 & $<1$ & 66 & 18 & $<1$ \\
\hline
\end{tabular}

Area sizes correspond to 96,48 and 24 well plates, respectively.

internalization process and preserve detection of cell surface $\mathrm{mIgM}$ by bound $\mathrm{Ab}$. Binding of these mAbs, as determined by SEM, to glutaraldehyde-fixed CRL 1648 $\mathrm{B}$-cell line is shown in Figures 1A-1F and demonstrates the low density expression of these mIgM molecules.

Using protein G-RBCs for cell surface $\mathrm{mAb}$ detection, cells pre-fixed with glutaraldehyde prior to the addition of the mAbs or mouse anti-huIgM sera preserve cell surface mAb detection at both $37^{\circ} \mathrm{C}$ and $4{ }^{\circ} \mathrm{C}$ (Table 4). These findings also indicate that the epitopes for the mAbs are preserved with glutaraldehyde fixation. SEM assays and protein G-RBC assays are both sensitive and robust, as in control experiments or isotype-matched HA, background gold-labeled goat anti-mouse Ig reagent (Figure 1I, 1J) or background rosetting, respectively, is not observed after glutaraldehyde fixation. A time-elapsed SEM series of micrographs is shown in Figure 1 (A and $\mathrm{B}$, compared to $\mathrm{K}$ and $\mathrm{L}$, respectively). At 15 mins (Figure $1 \mathrm{~K}$ ) and 30 mins (Figure 1L) of mAb4 incubation at $37^{\circ} \mathrm{C}$, followed by fixation to stop the internalization process, the majority of $\mathrm{mAb}$ internalization has already occurred even at the earliest time points measured (Figure $1 \mathrm{~K})$. Background goat anti-mouse Ig labeled gold is not observed.

Additional SEM studies show that mAb4-mediated internalization of mIgM by incubation of CRL 1648 cells at $37^{\circ} \mathrm{C}$ for 30 mins resulted in a lack of detectable mIgM on the cell surface by testing cells with the mAb panel or polyclonal mouse anti-huIgM heavy chain reagent for binding after the mAb4 incubation (Figure 1L). For example, in an additional confirmatory experiment using protein $\mathrm{G}-\mathrm{RBC}$ as the detection method, cells were exposed to $\mathrm{mAb} 4$ at $37^{\circ} \mathrm{C}$ for 30 mins, fixed, and then tested for mIgM expression using polyclonal mouse antihuIgM heavy chain reagent (similar to Table 4, live cells at $37^{\circ} \mathrm{C}, 30 \mathrm{~min}$ ). Lack of protein $\mathrm{G}-\mathrm{RBC}$ rosetting indicates a lack of residual cell surface bound $\mathrm{mAb} 4$ and an absence of mouse anti-huIgM heavy chain reagent detection of residual cell surface mIgM. Similar experiments testing mAb1-, mAb2-, and mAb3-mediated internalization of $\mathrm{mIgM}$ by incubation of CRL 1648 cells at $37^{\circ} \mathrm{C}$ for 30 mins also resulted in a lack of detectable mIgM on the cell surface using $\mathrm{mAbs}$ or anti-huIgM heavy chain reagent $(p$ $<0.05$ ). These finding suggest that all $\mathrm{mAbs}$ in the panel mediate virtually complete $\mathrm{mIgM}$ internalization, and thus each $\mathrm{mAb}$ recognized all forms of $\mathrm{mIgM}$ as defined by the mouse anti-huIgM heavy chain reagent reactivity. Similar results were observed in all mIgM-expressing
B-cell lines in our cell panel. At $1 \mu \mathrm{g} / \mathrm{ml}$ of $\mathrm{mAb} / 10^{6}$ $\mathrm{B}$-cells, internalization is complete at 30 mins $(p<0.05)$, suggesting this ratio represents a state of $\mathrm{mAb}$ excess for this cell line.

Table 4 (Rows 3 and 4) shows that, as with glutaraldehyde, low temperature also limited internalization. In addition, these results show that glutaraldehyde fixation did not substantially affect $\mathrm{mAb} 4$ binding to target (comparing results of Rows 1 and 2 to 3 and 4; Table 4). Timed experiments demonstrated that, by 30 mins at $37{ }^{\circ} \mathrm{C}$ (Table 4: Rows 9,10 ), the pre-treated cells' capacity to adsorb mAb4-HRP from solution is reduced, without a significant difference between PBS and acetate wash $(\mathrm{pH} 4.0)(p<0.05)$, suggesting that $\mathrm{mIgM}$ and $\mathrm{mAb} 4$ are predominantly internalized by 30 mins and are no longer free on the cell membrane to bind mAb4-HRP after acetate washing. The lack of residual cell surface mIgM resulted in no reduction of mAb4-HRP binding to mIgM solid phase in ELISA assays because cell mIgM was already internalized by pre-incubation with $\mathrm{mAb} 4$ at $37^{\circ} \mathrm{C}$. Thus, there was no mAb4-HRP absorption capacity by these cells whether they were washed with PBS or acetate $(\mathrm{pH} 4.0)(p<0.05)$. The robust mAbinduced internalization is demonstrated by lack of cell surface mIgM available for inhibition of mAb4-HRP or anti-huIgM test reagents subsequently used in ELISA assays. Similar experiments with each $\mathrm{mAb}$ confirmed mIgM internalization.

Experiments demonstrate that increasing cell culture times with $\mathrm{mAb} 4\left(\right.$ at $37{ }^{\circ} \mathrm{C}$ ) reduced the amount of cell surface $\mathrm{mIgM}$ as assessed by SEM, protein G-RBCs, and cell adsorption after the cells are washed in acid.

\section{Biologic activity}

Due to the uniqueness of the amino acid sequence of PDm and low homology to other GenBank sequences, we hypothesized that PDm may be involved in propagating receptor signaling functional activity to the cytoplasmic CD79 $\alpha / \beta$ TK signaling domain, as was reported for PDe [21]. Thus, growth, cell proliferation, apoptosis, and clonogenicity assays of CRL 1648 cells were performed to determine whether the anti-PDm mAbs modulated these processes. 


\section{Limiting dilution assays and cell density experiments}

Limiting dilution assays of CRL 1648 cells, growing with or without $1 \mu \mathrm{g} / \mathrm{ml}$ of $\mathrm{mAb} 4$, demonstrated significant growth inhibitory effects and decrease in cell survival in 10-day culture experiments (Table 5, Figure 2). Marked inhibition of growth was observed in wells plated with 20-1,000 cells per well (20 vs. 500 vs. 1,000 cells/ well). mAb4-treated wells did not achieve positive MTT signals, even when pooled, and remained at background level for the 10-day observation period. mAb4 depletion from solution by adsorption with fresh human CLLs resulted in a lack of detectable binding to PDm, the Perfect FOCUS $^{\mathrm{TM}}+$ IA purified fraction in solid-phase ELISA assays and growth inhibition properties. As cell growth in control wells achieved minimum cell numbers for positive MTT readings on days 2-4 of cell culture, the Student's $\mathrm{t}$-test was only applicable to time points from days 2 to day 10 , depending on the cell numbers plated and cell line. Growth curves shown in (Figure 2A, 2D-2I) present significantly different growth patterns in comparisons of $\mathrm{mAb} 4 v s$. isotype control $\mathrm{mAb}$ or comparisons of 1,000 vs. 500 vs. 250 or fewer cells/well.

Evidence of a significant caspase-dependent apoptotic effect by ELISA was found in residual cells at day 10 when compared to isotype control $\mathrm{mAb}(p<$ $0.05)$. At earlier time points no statistical caspase signal was detected (days 4-6). Thus, the major mechanism responsible for differential viable cell numbers, observed in days 4-10, was inhibition of single cell clone outgrowth as observed by phase contrast microscopy, rather than cell lysis. Caspase-positive wells were only obtained at days 8-10 $(p<0.05)$ indicating that apoptosis was a late event. The ability of stem cells to establish viable clones in limiting dilution conditions was impaired by $\mathrm{mAb} 4$ (Figure $2 \mathrm{~A}$ ), while $\mathrm{mAb} 1, \mathrm{mAb} 2$, and $\mathrm{mAb} 3$ only induced minor morphological changes and no change in cell numbers (Figure 2B, demonstrating lack of effect with $\mathrm{mAb} 1$ and $\mathrm{mAb} 3)$. Changing growth conditions, such as $\%$ Fetal Calf Serum (FCS), or the use of normal human serum or CLL patient serum added to the complete media, did not affect mAb4 inhibitory activity $(p<0.05)$ (data not shown). Removal of mAb4 at ten days, re-culturing cells, and re-examining viability and clonability-efficiency of residual cells revealed no growth of clones, even in the absence of mAb4 $(p<0.05)$ (data not shown). Thus growth of cells after 20 days, ten days with mAb4 followed by ten without $\mathrm{mAb} 4$, yielded no microscopically visible viable cells or MTT signal.

Because these anti-tumor effects of mAb4 were observed in experiments testing limiting-dilution clonal growth conditions, we investigated whether the mechanism of mAb4 inhibition is consistent with the blocking of a soluble autocrine or paracrine growth factor, or is directly dependent on stem cell frequency. These hypotheses may be distinguished by dilutions of sets of identical numbers of plated cells in different media volumes. If the absolute number of stem cells determines the cell growth kinetics in the presence of $\mathrm{mAb} 4$, then stem cell number is critical regardless of volume. If, however, increasing the volume of media of these same sets of plated numbers of viable cells reduces cell growth kinetics, then a soluble factor concentration is the critical determinant of growth in the presence of mAb4 (Table 5). We therefore examined whether the number of cells plated per well, or relative cell density or cells/volume media, as determined by well size and media volume, correlate to optimal mAb4 anti-tumor effects. These experiments tested whether the mAb4 effect is directly modulating the functional activity of stem cells by inducing stem cell apoptosis or is competing with prosurvival and growth factors secreted by stem cells.

We found that mAb4 can suppress outgrowth of the most potent clonogenic cells, those capable of establishing single cell clones (at 1-5 cells per well). Other stem cells present at lower frequency can rescue clone development if sufficient cells are plated in the presence of mAb4. For example, if the critical stem cell was present at a frequency of 1 in 500 cells, this absolute number of 500 cells per well would be predicted to produce viable clones regardless of cell density/volume. However, we found a consistent inverse cell/volume-dependent growth pattern observed when identical numbers of cells were plated in increasing media volumes and surface areas available for growth in wells (Table 5). These findings suggest that cell density/volume media is also a determinant of B-cell survival in the presence of $\mathrm{mAb} 4$, along with absolute cell number, and thus concentrations of an as yet undefined secreted growth factor may be critical.

In this cell density/volume media experiment (Table 5), we observed significant differences $(p<0.05)$ between the 96-well viable cell counts, the 48 -well viable cell counts and the 24-well viable cell counts, despite plating the same number of cells ( 10 or 50 cells per well) in each experiment, for each cell line tested. The results are consistent and show that plating the same number of cells in a smaller volume results in greater outgrowth or clone formation in mAb4-treated cells, although both wells are still reduced in viable cell number compared to isotype-matched control $\mathrm{mAb}$. Thus, while $\mathrm{mAb} 4$ still suppresses cell growth up to 500-1,000 cells per well, its effect is lessened when cell density is increased (Figure 2I). These data also show significant differences for each comparator case of same cell number per well $v s$. well size and volume. Control wells treated with isotype-matched $\mathrm{mAb}$, plated at $1-5$ cells per well, consistently produced clones with these cell lines. This experiment was expanded to include different $\mathrm{mAb}$ dilution experiments examining concentrations from $1 \mu \mathrm{g} / \mathrm{ml}$ to $20 \mu \mathrm{g} / \mathrm{ml}$. The inhibition of growth of the mIgM-expressing B-cell line, CRL 1648, by $\mathrm{mAb} 4$ over ten days was tested at cell dilutions of 20 , 100, 250, 500, and 1,000 cells/well. As shown in Figure 
2I, mAb4 inhibited growth in the mIgM-expressing B-cell line, CRL 1648, for a 10-day period, but not when the concentration of cells plated was greater than 500-1,000 cells/well. These anti-clonogenic effects were confirmed by timed microscopic observations, which demonstrated that it was the inability of single cells to replicate (self renewal) and establish clones over the first 4-10 days of culture that was primarily responsible for reduced cell numbers. As a secondary effect, these mAb4 nonclonogenic cells subsequently became caspase-positive, undergoing apoptosis by days 8-10.

Similar experiments using control $\mathrm{mIgG}$-expressing cells did not show any of the mAb4-induced biologic effects, and anti-PD mAb2, commercial polyclonal rabbit, mouse, or goat anti-huIgM was not anti-clonogenic with $\mathrm{mIgM}+$ or $\mathrm{mIgG}+$ cells in this assay, despite previous evidence that it internalizes the receptor (Figure 2B). These results suggest that the amino acid sequence determining functional growth inhibition is located in a neo-epitope defined by mAb4.

These MTT assays were extended to the cell lines shown in Figure 2, where a variety of mIgM B-cell lines were examined for mAb4-induced inhibition of cell growth and apoptosis. These experiments indicate that mAb4-induced inhibition was a general phenomenon in mIgM-expressing cells. mAb4 induced growth inhibition of mIgM-expressing B-cell lines, including CRL 1648 (Figure 2A), CRL 2958 (Figure 2D), CRL 1596 (Figure 2E), CRL 1432 (Figure 2F), CRL 2260 (Figure 2G), and CRL 1647 (Figure 2H).

\section{DISCUSSION}

For B-cell leukemia and lymphoma, an abundance of evidence supports the contention that the BCRC itself drives the malignant phenotype [13, 32-37]. The concept that either an antigen encounter or persistent receptor stimulation is the basis for the constitutively activated BCRC state is supported by the finding that CLL cell immunoglobulin heavy chain variable region $(\mathrm{IgVH})$ genes are often derived from a restricted repertoire [12, 38-44]. As naïve B-cells encounter antigens in germinal centers, and the $\mathrm{IgVH}$ mutation-based maturation process is initiated, two distinct early B-cell subtypes emerge as progenitors of CLL. In one case, the malignant B-cell does not enter the somatic mutation phase $[38,43]$. Unmutated IgVH cells have phenotypes consistent with weak poly-auto-reactive targets, including a subset that is self-reactive to the BCRC $[38,43,44]$. In an environment of continuous stimulation of the BCRC and maximum BCRC-dependent signaling, patients are noted to have poor outcomes compared to the progenitor B-cells undergoing somatic IgVH mutations [44, 45].

In addition to these BCRC events, there is clear evidence that environmental factors play a critical role in providing different levels of co-antigenic stimulation, as well as other growth promoting factors [46-52]. Those cells undergoing somatic mutation may also exhibit autoreactivity and respond to microenvironment-derived factors promoting growth in the absence of appropriate apoptosis [46-52]. For example, bone marrow and lymph nodes appear to be favorable sites for CLL proliferation while the blood appears to be less favorable [47, 53, 54]. The more recent observations of a drug-induced lymphocytosis linked to clinical response may correlate with increased vulnerability of these cells due to loss of bone marrow/lymph node environmental pro-survival factors [46-54]. Investigations into environmental regulatory factors and the constitutively activated BCRC state were the basis of the screening and testing of $\mathrm{mAb}$ anti-tumor effects at limiting dilution conditions as a model to tease out the individual factors that play a role in cell survival $[28,29,30]$. Results presented here directly implicate external factors as determinants in cell survival in mAb4 treated cells (Table 5). This model facilitates further investigation and identification of the factors opposing mAb4-induced anti-tumor effects.

The identification of the $\mathrm{BCRC}$ as the initiating oncogenic stimulus is strikingly similar to the biology of Chronic Myelogenous Leukemia (CML), which is a model of an initial "one translocation event" mutation generating the single protein driver of malignancy [55]. Rational drug design targeting the translocation-induced constitutively activated TK in CML has lead to a marked improvement in clinical outcomes [55]. This example emphasizes the advantages of identifying the molecular structure initiating and maintaining the malignant phenotype. The continued growth-promoting stimulation by the activated BCRC would be expected to select for an accumulation of mutation variant clones in the downstream TK pathways, despite initial good clinical response to downstream TKI [16-18]. These finding suggest that anti-BCRC therapy may have maximum clinical benefit if administered early in the course of disease to suppress BCRC downstream stimulation, cell division, and mutational events, and thus control the disease in the chronic phase as has been demonstrated in CML therapy [55]. Early therapeutic intervention may, in general, be critical to achieve more robust outcomes. mAbs presented here provide an opportunity for direct targeting of the $\mathrm{BCRC}$, the initiating factor in almost all B-cell malignancies.

"Chronic Active BCRC Signaling" has been identified in the activated B-cell-like (ABC) subtype of DLBCL. The BCRC was found to be present in microclusters on the cell membrane, driving cell growth [2427]. The current SEM investigations reveal similar but smaller complexes of mIgM clusters present to variable degrees in all the B-cell lines tested in our panel (Figure $1 G)$. This finding may suggest a more universal role for small mIgM clusters ("small micro-clusters") as a mechanism for signal amplification and as a potential marker of prognosis [26]. As the SEM experiments 
represent results of glutaraldehyde-fixed cells, the clustered formations were not induced by $\mathrm{mAb}$, but rather detected by our $\mathrm{mAb}$ panel. The mIgM cluster shown in Figure $1 \mathrm{G}$ may not be identical to those described for the ABC subtype of DLBCL, but may be functionally active. SEM investigations of $\mathrm{mAb}$ binding to DLBCL (not shown) demonstrated more intense gold clustering which may represent the classical micro-cluster, but further investigation is needed to classify these entities by size and function. As mAb4 induced growth inhibition, even in B-cell lines demonstrating increased clustering, this molecular event does not appear to confer resistance to mAb4 (Figure 2) nor does the clustering itself block the mAb4-binding epitope (Figure 1A-1C).

The depiction of the "mIgM-signalasome" has often been simplified, and betrays the complexity and redundancy that is known to be wired into B-cell activation, especially pathways from the stromal microenvironment [46-54], pathways across the membrane surface [56, 57] and by interactions with numerous cytoplasmic mediators [4,6,58-62]. Taken together, investigations presented here, regarding the robust and specific biologic effects mediated by mAb4, demonstrate that the BCRC remains the central controlling element of oncogenesis (Figure 2). Cell membrane-associated proteins contribute to $\mathrm{BCRC}$-dependent downstream signaling. For example, CD19 is a B-cell trans-membrane molecule that associates with the BCRC and is critical for $\mathrm{B}$-cell activation [57]. Additionally, BCRC signaling is modulated by a net balance of CD19 and CD22 effects [63]. While CD19 is thought to amplify the signal generated through the BCRC, CD22 acts as an inhibitor [64-71]. These examples demonstrate how multiple extracellular and trans-membrane signaling pathways fine-tune the BCRC control of B-cell kinetics and the malignant phenotype.

A therapeutic strategy of BCRC cross-linking and internalization might be expected to disrupt or eliminate BCRC-dependent signal transduction. However, experimental evidence suggests that this is not the case and internalized BCRC continues to regulate cell processes [15]. Data presented here confirm these reports and demonstrate that the epitope directing cross-linking is critical in determining post receptor internalization events (Figure 2A vs. 2B). Anti-PD mAbs induce a state where cell surface $\mathrm{mIg}$ is no longer detected (by SEM using an anti-huIgM reagent). However, in this BCRC cell surface expression-negative state, no growth-inhibition effects are measured. While in contrast, the mAb4induced BCRC negative phenotype results in growth inhibition and apoptosis (Figure 1I, Figure 2). Similarly, CD79 $\alpha / \beta$ is critical in $\mathrm{mIgM}$-directed signal transduction and is co-internalized with mIgM by anti-PD mAbs but continues to signal in its internalized state [15]. AntiCD79 Abs have also been evaluated for internalizing capability, and growth-inhibitory effects. One anti-
$\mathrm{CD} 79 \alpha / \beta \mathrm{mAb}$, being developed as a "carrier mAb" to deliver cytotoxics to lymphoma cells, inhibits growth of B-cells [72]. In addition to the IgVH mutation prognostic status association, strong negative prognoses correlate to cytogenetic findings such as del 17p, associated with p53functional impairment. Patients with tumors exhibiting p53 abnormalities have rapid disease growth and poor survival [73]. While this abnormality is believed to be remote from the BCRC and its immediate pathways, it is now well established that inhibition of Bruton's TK in the clinic reverses the rapid growth of these tumors, mediates response, and reduces the poor prognosis implications [73]. These findings further confirm the dominant role of inhibition of BCRC activation over distal regulatory cellular processes and survival outcomes. In the absence of growth stimulation induced by the BCRC, p53 antiapoptotic abnormalities become less critical.

As progress has been made in selecting molecular targets for therapy, the therapeutic modalities themselves have evolved and have become more potent. New anti-CD20 Abs show increased efficiency of effector mechanisms of cytotoxicity. Engineered T-cell directed therapies, such as bi-specific [74] or T-cell chimeric antigen receptors [75], have demonstrated robust and specific targeted-restricted cytotoxicity, resulting in an almost surgical-precision resection of antigen-expressing tissue. However, the discovery of more tumor-specific targets has lagged in comparison to the increased potency of the cytotoxic mechanism, resulting in prospects of vast numbers of patients suffering with severe or complete B-cell depletion. The mAbs generated here offer a better focused targeting system more applicable to these potent drug or T-cell directed therapeutic modalities [74, 75]. Extensive specificity studies were conducted, which demonstrated the lack of epitope expression in epithelial or other lymphatic tissues and lack of cross-reactivities of these mAbs to unrelated proteins (Table 1A-E). Data regarding the specificity of $\mathrm{mIgM}$ receptor targeting and internalization kinetics suggest that all four mAbs could reduce normal tissue toxicity when compared to currently utilized "mAb targeting agents".

Here we show the internalizing kinetics of the $\mathrm{mAbs}$, the identity of the mAbs reactivity with anti-huIgM sera and the completeness of $\mathrm{mIgM}$ internalization by each mAb (Table 2, 3, Figure 1A vs. 1I). Results of the SEM, protein G-RBCs, and cell adsorption timed experiments demonstrate that increasing times of mAb4 exposure (30 minutes at $37^{\circ} \mathrm{C}$ ) specifically reduced the amount of cell surface mIgM to undetectable levels. Thus, with these mAbs, salvaging IgG- and IgA-expressing B-cells may be feasible, which would reduce the immune-suppression common with current treatments (Figure 2A vs. 2C).

In addition, an understanding of the spatial binding characteristics and epitope definition of each of the mAbs is critical in determining structural-functional relationships of their defined epitopes in macromolecules, and whether 
any of these epitopes have natural regulatory-ligands. The identification of biologically active epitopes may help detect and characterize possible natural binding regulatory ligands by affinity chromatography. For clinical utility, determining whether multiple mAbs can bind simultaneously to the target protein and what biological effects each may induce, will contribute to rational drug development. For example, if three mAbs from our panel each bind to different epitopes, and do not interfere quantitatively with each others' binding, then the amount of drug-bound-mAb delivered to the cell could increase substantially by using combinations of mAbs or even combinations of synergistic drug conjugates. Thus, further clinical studies will reveal the utility of the mAb panel presented here in targeted leukemia and lymphoma therapies.

\section{MATERIALS AND METHODS}

\section{Generation of hybridomas and reagents}

Immunogens and constructs: To isolate mAbs reactive with the target peptides, PDmpeptide EGEVSADEEGFEN, PDg-peptide ELQLEESCAEAQDGELDG, and immunogens carrying these peptides were constructed via glutathione-Stransferase methodology (GST) [76] (Promega, Madison, WI, USA; Rockland Immunochemicals, Limerick, PA, USA), or purchased as Multiple Antigen Peptide (MAP) PDm or PDg (Bio-Synthesis, Lewisville, TX, USA) and Keyhole Limpet Hemocyanin (KLH) PDm or PDg (Bio-Synthesis). GST, MAP, and KLH constructs were used as immunogenic covalently bound carrier proteins and sets of mice (six mice per set) were immunized with one protein, or combinations of the proteins carrying the target peptide. Due to relative hydrophobicity of the PDm peptide, both n-terminal and c-terminal KLH peptides were generated (Bio-Synthesis) for immunizations and for screening hybridoma supernatants. Eight constructs, including free EGEVSADEEGFEN (PDm), free ELQLEESCAEAQDGELDG (PDg), GSTEGEVSADEEGFEN, MAP-EGEVSADEEGFEN, KLH-EGEVSADEEGFEN, EGEVSADEEGFEN-KLH, KLH-EGENSADEEGFEN (mIgM isomer 1), and KLHEGEVSADEEGFEN (mIgM isomer 2), were available for immunizations and for screening clones. The common overlapping sequences of $\mathrm{PDe}$ and $\mathrm{PDd}$ were also tested in screenings to further establish specificity (BioSynthesis). These multiple constructs, and the available free GST, MAP, and KLH, allowed for rapid screening and elimination of hybridoma clones reactive with carrier proteins or peptide conformations dependent on carriers or their linkers.

Immunization and hybridoma screening: Groups of mice, six mice per group, were immunized comprising 20 distinct immunization strategies of adjuvants, immunogens, and murine genetic backgrounds. Clones of interest were labeled according to fusion number, clone number, and immunization strategy.

Pre- and post-mouse-immunization serum was collected, diluted 1:100, and tested for peptidespecific activity in ELISA (Promega) to select mice for fusions [77]. Initial low titer sera and low peptide immunogenicity was observed and this finding was consistent with failed previous efforts to produce high affinity anti-PDm and anti-PDg mAbs. In contrast, this genetic background is appropriate to produce anti-mIgE mAbs $[21,78,79]$. Testing hybridoma supernatants also confirmed that when $\mathrm{mAb}$ was purified and adjusted for concentration, the mAbs were weak binders in ELISA assays. Screening assays were then designed to exclude low affinity mAbs. Selected mAbs were purified from hybridoma supernatants, utilizing rapid micro-protein $\mathrm{A}$ chromatography purification (Thermo-Fisher Scientific, Pittsburgh, PA, USA), and tested in protein concentrationdependent dilution ELISA assays [77]. New strategies, including extending the peptides into the $\mu \mathrm{C} 4$ domain 4 region ("extended peptide" 18 mer (Bio-Synthesis)) to possibly capture conformational epitopes, using highly purified target protein for boosts, and testing a variety of mouse strains and new adjuvants, resulted in six mice with post immunization serum (1:100) titers of $>1: 10,000$. These mice were selected for hybridoma generation and three clones were isolated that were active in binding to the eight target constructs, maintaining good ELISA reactivity in dilutional assays $(<10 \mathrm{ng} / \mathrm{ml})$. Two clones were specific for $\mathrm{mIgG}$ and $\mathrm{PDg}$.

Purified mIgM enrichment for immunization and screening: Upon generation and isolation of our first anti$\mathrm{PD} \mathrm{mAb}(\mathrm{mAb} 1)$ and completion of initial specificity testing, mAb1 was incorporated into immune-affinity chromatography (AminoLink ${ }^{\mathrm{TM}}$ Plus Immobilization Kit, $2 \mathrm{ml}$; Thermo-Fisher Scientific; Pierce Inc., Rockford, IL, USA) to enrich cell lysates for native mIgM. Patient FicollPaque Plus (GE Healthcare Life Sciences, Piscataway, NJ, USA) purified CLL cells or cell lines (CRL 1648) were used as a source for native mIgM in $0.05 \% \mathrm{NP}$ 40 (Sigma-Aldrich, St. Louis, MO, USA), and PerfectFOCUS $^{\mathrm{TM}}$ - membrane protein extraction technology (G Biosciences, St. Louis, MO, USA; Pierce Inc.) cell extract fractions were used for assays and further mouse immunizations. Perfect-FOCUS ${ }^{\mathrm{TM}}$ - membrane protein extraction technology removed ionic detergents, charged molecules, and cytoplasmic proteins by precipitating membrane proteins, which were subsequently collected by centrifugation ( $\mathrm{G}$ Biosciences). The protein pellet was solubilized in immunogen buffer or $\mathrm{pH} 8.6$ Tris $0.5 \mathrm{~N}$ $\mathrm{NaCl}$ buffer for further mIgM purification by immune chromatography or applications as native $\mathrm{mIgM}$ for immunization. In these later immunizations, sets of mice 
were initially immunized with PD immunogens, KLH or MAP, and then boosted with lysate fractions containing $\mathrm{mIgM}$ to capture conformational epitopes.

The $\mathrm{mIgM} / \mathrm{mIgG}$ molecules were proven to be expressed by the selected lymphoma cell line panel using RNA primers specific for PDm and PDg by RT-PCR, and were shown to be present in the cell membrane fraction by Western blot analysis [22]. PDd was tested by RT-PCR in select cell lines used for immunization and was found to be expressed in all lines tested. PDd, PDa, and PDg, and the common overlapping sequence of PDe, were generated and tested for $\mathrm{mAb}$ reactivity because purified CLL cell lysate fractions likely contained these PD constructs as contaminants (eg PDd). The mIgM and $\mathrm{mIgG}$ fractions were collected by Perfect-FOCUS ${ }^{\mathrm{TM}}$ - membrane protein extraction technology ( $\mathrm{G}$ Biosciences), which yielded enriched $\mathrm{mIgM}$ or $\mathrm{mIgG}$ preparations from human CLL cells and cell lines CRL 1432, Namalwa mIgM-L Burkitt's lymphoma, CRL 1596, Ramos cIgM mIgM-L Burkitt's lymphoma, CRL 1647, ST 486, cIgM mIgM-K Burkitt's lymphoma, CRL 1648, CA 46, mIgM-K Burkitt's lymphoma, CRL 1649, MC 116, mIgM-L undifferentiated lymphoma, CRL 2260-HT, mIgM-K Diffuse mixed B-cell lymphoma, CRL 2958, SU-DHL-5, mIgM-L Diffuse large cell lymphoma, CRL 2632, Pfeiffer, IgG-K Diffuse large cell lymphoma, and CRL 2289, DB, mIgG-L Large B-cell lymphoma (Large B-cell lymphoma expressing $\mathrm{mIgG}$ ), adequate for robust signals in ELISA studies. These assays were used to further demonstrate specificity and consistency of $\mathrm{mAb}$ reactivity to antigen, and lack of cross-reactivity.

Specificity screening: Using the above screening methodology, candidate mAbs were collected for further analysis. Comparative binding of purified mAb1, mAb2, and $\mathrm{mAb} 3$ demonstrated the highest specific ELISA signal of the anti-PDm mAbs when tested against each of the eight constructs in ELISA assays and the lysates from the mIgM-expressing cells listed in the previous section. Clones with lower anti-PDm reactivity in the ELISA assays were then tested against the purified Perfect-Focus ${ }^{\mathrm{TM}}$ Immune Affinity Chromatography mIgM fraction (mAb1). One mAb, designated mAb4, showed enhanced reactivity with the purified fraction compared to the anti-PDm ELISA assay. To confirm mIgM specificity, these clones were tested against viable B-cell lines in HA [34], in SEM against +/- glutaraldehyde-fixed B-cells, and against purified sIgM (Promega) in ELISA assays.

\section{Candidate mAb panel}

The $\mathrm{Ab}$ designated mAb1-1, produced by a hybridoma cell line from fusion 117, Ab designated $\mathrm{mAb} 2-2 \mathrm{~b}$, produced by a hybridoma cell line from fusion 118 , Ab designated mAb3-2b, produced by a hybridoma cell line from fusion 118, and $\mathrm{Ab}$ designated mAb4-
$2 \mathrm{~b}$, produced by a hybridoma cell line from fusion 119 , were collected as the clinical candidate "panel of mAbs". mAb1-1 was designated Group 1 as it was derived from a fusion comprising a mIgM-PD peptide-MAP immunogen only. All other Abs were designated as Group 2 as they were generated using boosts of various purified mIgM fractions in addition to the PDm-MAP immunogen. Further, these mAbs (mAb2, mAb3 and mAb4) were designated as Group $2 \mathrm{~b}$, as the purified $\mathrm{mIgM}$ was derived from cell line b (CRL 1648) extract.

\section{Cell line panels}

Lymphoid cell panel: CRL 1432, Namalwa mIgM-L Burkitt's lymphoma, CRL 1596, Ramos, cIgM mIgM-L Burkitt's lymphoma, CRL 1647, ST 486, cIgM mIgM-K Burkitt's lymphoma, CRL 1648, CA 46, mIgM-K Burkitt's lymphoma, CRL 1649, MC 116, mIgM-L undifferentiated lymphoma, CRL 2260-HT, mIgM-K Diffuse mixed B-cell lymphoma, CRL 2958, SU-DHL-5, mIgM-L Diffuse large cell lymphoma, CRL 2632, Pfeiffer, IgG-K Diffuse large cell lymphoma, CRL 2289, DB, mIgG-L Large B-cell Lymphoma, and CRL 2568, H2.8 murine IgG1-K Myeloma were obtained from the American Type Culture Collection (ATCC, Manassas, VA, USA) specifically for these experiments. These cell lines were maintained in RPMI 1640 with 50 units penicillin/streptomycin, $2 \mathrm{mM}$ glutamine, and $7.5-15 \%$ fetal bovine serum, and were incubated at $37{ }^{\circ} \mathrm{C}$ in $5 \% \mathrm{CO}_{2}$. The ATCC authenticates and tests cell lines provided for research as per their protocols.

Epithelial/non-lymphoid cell panel: Human colon cancer cell lines (six lines), human breast cancer cell lines (six lines), human lung cancer cell lines (six lines), human Melanoma cell lines (four lines), and human sarcoma cell lines (two lines) were obtained from our cell and tissue bank. The authenticity of these cell lines were tested by immune-phenotyping against a panel of defined mAbs.

Breast: BT 474, SK BR7, CaMa-1, BT-20, MCF-7, SK Br-3, MDA-MB 453, MDA-MB 436, and MDA-MB 468.

Lung: H64, SW1271, DMS 78, SK-LU-9, NCI H596, A549, NCI H1105, NCI H69, and DMS 53. Melanoma: SK MEL- 29 and MeWo.

Colon: T84, SW1222, Colo 205, Lim 1215, HT-29, DLD-1, SW1116, SW 620, SW 480, LoVo, HCT-15, and HCT-116.

Sarcoma: HT-1080 and U2OS.

Human serum samples from patients and normal volunteers (found specimens) were collected under Institutional Review Board-approved research and collected into our cell sera and tissue bank over many years. 


\section{Ensuring the specificity of commercial regents}

As these ELISA assays depend on the ability to detect a mouse Ig binding to a human mIgM, highly specific reagents are required. These assays comprise a set of target Ig proteins that are expressed in low concentrations and the detecting reagents are immunologically closely related Ig molecules of various species, thus cross-reactivity was a major obstacle and assay development was a critical aspect of specificity assessment. The ELISA assays were designed to enhance sensitivity for detection of mIgM by using a goat antihuIgM capture antiserum bound to the solid phase. This methodology promotes the binding of both human cytoplasmic IgM (cIgM) and $\mathrm{mIgM}$, which is present in low concentrations in NP-40 cell lysates. Increasing the total IgM binding capacity to solid phase resulted in enhanced assay sensitivity by increasing both $\operatorname{cIgM}$ and mIgM binding to plates $(p<0.05)$. To reduce non-specific background, the goat anti-huIgM capture serum needed to be pre-adsorbed with sepharose bound-mouse Ig.

The detection system consisted of a goat antimouse-Ig-HRP labeled reagent, pre-adsorbed with sepharose-bound huIgM and determined in separate assays not to be reactive with human $\mathrm{mIgM}$ or sIgM. However, the adsorbed goat anti-mouse Ig-HRP did detect mouse $\operatorname{IgM~} \mathrm{mAb}$ in hybridoma supernatant. When a mouse hybridoma IgM was present, it was found bound nonspecifically to the solid phase as the pre-adsorbed goat anti-huIgM capture anti-serum also detected and bound mouse hybridoma IgM, rendering all IgM-producing mouse hybridoma clones as false positives in the screen. Thus, rather than continue with further adsorptions of reagents, an additional ELISA assay using protein G-HRP detection reagent was also tested as a control, as hybridoma IgM, $\operatorname{sgM}$, cIgM, and $\mathrm{mIgM}$ were not detected in this protein G-HRP assay. While the protein G-HRP assays removed positive and false positive IgMsecreting hybridoma results, the more sensitive goat antimouse Ig reagent allowed better detection of all mouse Ig subclasses. However, the protein G-HRP reagent required the capture reagent to be a $\mathrm{F}(\mathrm{ab}) 2$ product to avoid protein $\mathrm{G}$ binding to capture reagent.

\section{Hemadsorption/Hemagglutinin assays}

HA assays were carried out as described previously $[77,80]$. As the HA assay was originally designed to rapidly assess $\mathrm{Ab}$ cell-surface binding to adherent target cells, the assay was adapted here for use in the generally non-adherent B-cell panel. Non-adherent or weaklyadherent test cells are first exposed to $\mathrm{mAb}$ in eppendorf tubes, washed, then exposed to protein G-RBCs at $4{ }^{\circ} \mathrm{C}$ and examined under phase contrast microscopy on diluted feathered glass slides. HA resulted in large complexes of
Ab-coated target cells cross-linked by protein G-RBCs. HA was scored as the number of un-reacted target cells (non-RBC rosetting cells) per un-reacted control assay target cells. This assay rapidly assesses if $>99 \%$ of target cells are rosetted (hemeagglutination), and thus evaluates, on a single-cell basis, heterogeneity of $\mathrm{mIgM}$ expression. The protein G-RBC also weakly detected IgG-expressing B-cells without the addition of $\mathrm{mAb}$, indicating its binding to surface-expressed $\mathrm{mIgG}$. However, this binding was blocked by pre-incubation of protein G-RBCs with control IgG2a (mAbA33), which specifically blocked rosetting HA using protein G-RBCs, demonstrating the specific reactivity of the protein G-RBCs for cell surface Ig. Percent rosetted target cells $=($ control $\mathrm{mAb}$ tested cell unrosetted - positive mAb tested cell un-rosetted) / control $\mathrm{mAb}$ tested cell un-rosetted X $100 \%$. HA assays were scored using phase contrast microscopy $(100 \mathrm{x})$ as neg $(<$ $1 \%),+(>1 \%),++(>90 \%)$, or $+++(>99 \%)$.

\section{ELISA sandwich assay of cell lysates}

Of note is that all lymphoma cell lines used contain cytoplasmic IgM (variously glycosylated, but similar to serum IgM). Thus, these assays based on cell extracts neither confirm nor assess $\mathrm{mAb}$ specificity and are unable to distinguish $\mathrm{mAb}$-specific reactivity between $\mathrm{mIgM}$ and serum or cytoplasmic IgM. Thus, cell membrane IgM binding specificity was determined by cell surface binding experiments utilizing viable cells. Protein labeling kits for HRP (Sigma-Aldrich; Pierce Chemicals) were used to directly label purified $\mathrm{mAb}$ for use in a solid phase ELISA assay, as per manufacturer's directions.

To test $\mathrm{mAb} /$ supernatant reactivity to extracts of CRL 1648-mIgM and CRL 2289-mIgG, a specific "murine Ig-adsorbed" goat $\mathrm{F}(\mathrm{ab}$ ')2 anti-human IgMFc or anti-IgGFc anti-sera capture $\mathrm{Ab}$ was attached to solid phase plastic in $0.5 \mathrm{M}$ Tris $0.15 \mathrm{M} \mathrm{NaCl} \mathrm{pH} 8.0$, Nunc MaxiSorp ${ }^{\circledR}$ flat-bottom 96 well plate (eBioscience, San Diego, CA, USA). The NP-40 lysate of CRL 1648 or CRL 2289 , or the control breast cancer cell lysate, BT-474, was added to the wells. The CRL 1648 lysate provided human mIgM, and CRL 2289 lysate provided $\mathrm{mIgG}$ to bind the capture $\mathrm{Ab}$. The wells were then washed three times. As BT-474 breast cancer cell line lysate did not provide protein binding to capture $\mathrm{Ab}$, this was used as a control to test for cross-reaction of the $\mathrm{mAb}$ to the capture system, or cross-reaction of the capture system to the mAb detection reagents used in the ELISA assay $[81,82]$. Due to excess cytoplasmic IgM or IgG contaminating NP-40 extracts of CRL 1648 or CRL 2289 respectively, additional membrane protein concentrating strategies, such as Perfect-FOCUS ${ }^{\mathrm{TM}}$ were employed. Application of the Perfect-FOCUS ${ }^{\mathrm{TM}}$ technology Membrane Proteins kit (G-Biosciences) after NP-40 lysis also reduced the NP-40 concentration in the enriched antigen fraction. For the majority of assays, CRL 1648 lysis fraction was used unless indicated otherwise 
(Table 1). Once anti-PD mAbs were established, immuneaffinity column chromatography (mAb1) provided further enriched quantities of mIgM from Perfect-FOCUS ${ }^{\mathrm{TM}}$ fractions (still partially complexed with CD79 $\alpha / \beta$, as determined by Western blot analysis), which was appropriate for in vitro assays and immunizations.

The Perfect-FOCUS ${ }^{\mathrm{TM}}$ technology Membrane Proteins kit (G-Biosciences) was used as directed by the manufacturer. Cells $\left(2 \times 10^{6}\right)$ were suspended in FOCUS ${ }^{\mathrm{TM}}$ Extraction Buffer-V (urea CHAPS buffer) and then lysed by sonication. Protein samples were treated with UPPAreagents, a proprietary precipitation agent. Protein pellets were collected by centrifugation in a microcentrifuge tube and interfering agents were pipetted away with washes in Orgosol buffer provided with the kit. Precipitated protein was dissolved in $1 \mathrm{ml}$ Extraction Buffer-V as a stock solution.

As above, to test the relative reactivity of the panel of mAbs to extracts of CRL 1648-mIgM and CRL 2289$\mathrm{mIgG}$, a specific murine Ig-adsorbed goat anti-human IgMFc or anti-IgGFc anti-sera capture $\mathrm{Ab}$ was attached to solid phase plastic, in $0.5 \mathrm{M}$ Tris $0.15 \mathrm{~N} \mathrm{NaCl} \mathrm{pH} 8.0$ (eBioscience). The NP-40 lysate/Perfect-FOCUS ${ }^{\mathrm{TM}}$ fraction of CRL 1648 or CRL 2289, control human serum lysate, or control breast cancer cell lysate, BT-474, was added to the wells. The CRL 1648 lysate provided human $\mathrm{mIgM}$, and CRL 2289 provided $\mathrm{mIgG}$, to bind the capture $\mathrm{Ab}$. The wells were then washed three times. Purified mAb was then added to wells in which specific mAbs had bound to the captured human $\mathrm{mIgM}$ or $\mathrm{mIgG}$, which was in turn bound by either the capture anti-human IgMFc or IgGFc (Promega) forming a goat anti-human-IgMFc-mIgM-mAb complex or goat anti-human-IgGFc-mIgG-mAb complex. The mouse $\mathrm{mAb}$ was then detected with specific goat antimouse Ig, labeled with HRP (preabsorbed with human IgM-sepharose or human IgG-sepharose). Hybridoma supernatants were added, and specific mAbs detecting captured human $\mathrm{mIgM}$ or $\mathrm{mIgG}$, which was bound by the capture anti-human IgMFc or IgGFc, formed a goat anti-human-IgMFc-mIgM-mAb complex or goat antihuman-IgGFc-mIgG-mAb complex. The mouse mAb is then detected with specific HRP labeled goat anti-mouse Ig (preabsorbed with human IgM-sephrose or human IgGsepharose) (Thermo Fisher Scientific). Other positive cell extracts from our B-cell panel yielded similar results.

Specificity of reactivity was further confirmed using mIgE derived from human B-cell line SK007 (human B-cell line expressing $\mathrm{mIgE}$ without $\mathrm{mIgM}$ ) by NP-40 lysis of SK007 cells, and was tested with ELISA using specific goat anti-human $\mathrm{IgE}$ capture $\mathrm{Ab}$. To eliminate the possibility of reactivity with transmembrane or cytoplasmic domains (KVK), HA assays were carried out, and fluorescent microscopy (FM), using fluorescent labeled goat anti-mouse Ig pre-absorbed with CLL cells, was used to detect $\mathrm{mAb}$ bound to fresh viable CLL cells. Additional assays were carried out with selected hybridomas to assess relative affinity by testing $\mathrm{mAb}$ purified from supernatant added to wells at $0.1 \mu \mathrm{g} / \mathrm{mL}$ and serially diluted $2 \mathrm{X}$. This allowed for removal of clones secreting low affinity mAbs. Inhibitory ELISA assays were carried out by incubation of purified $\mathrm{mAb}$ with inhibitor for 30 mins at $4{ }^{\circ} \mathrm{C}$ and centrifuged to remove complexes prior to addition of $\mathrm{mAb}$ to ELISA plates. $\mathrm{mAb}$ concentration was adjusted based on dilutional effects of the inhibitor to maintain a concentration of $\mathrm{mAb}$ at 0.1 $\mu \mathrm{g} / \mathrm{ml}$.

\section{mAb-induced internalization experiments}

Using a sensitive alternative methodology, such as adsorption, to assess relative residual cell surface $\mathrm{mIgM}$ levels at various time points after mAb exposure, viable B-cell lines were exposed to either glutaraldehyde (cells fixed as per SEM protocol) or PBS (Table 4). In glutaraldehyde-fixed cells, no internalization occurs and cells exposed to mAb4 first do not allow subsequent mAb4-labeled HRP adsorption as the epitope is already blocked by mAb4. Thus, testing the adsorbed solution of mAb4-HRP in ELISA assays after absorption by mAb4coated antigen of glutaraldehyde fixed cells, yields maximum binding, which is then set as $100 \%$ binding for each cell line (Table 4, Row 1). Groups of viable (PBS) cells were exposed to $10 \mu \mathrm{g} / \mathrm{ml} \mathrm{mAb4}$ at $4{ }^{\circ} \mathrm{C}$ for 5 mins (Table 4, Rows 3 and 4), or at $37^{\circ} \mathrm{C}$ for 5 mins (Table 4, Rows 5 and 6), 15 mins (Table 4, Rows 7 and 8 ), or 30 mins (Table 4, Rows 9 and 10). At the end of the incubation periods, cells were washed with cold PBS pH 7.0 (Table 3, Rows 5, 7, and 9) or $0.5 \mathrm{M}$ acetate $0.5 \mathrm{~N}$ $\mathrm{NaCl}$ pH 4.0 solutions (Table 4, Rows 6, 8, and 10) for 10 mins on ice, then washed in $\mathrm{pH}$ 7.0 PBS to re-equilibrate cell pellets to physiologic conditions and fixed with glutaraldehyde and washed again prior to adsorption [83].

\section{Western blot analysis}

Western blot analysis was carried out as previously described [22]. Samples were boiled in electrophoresis sample buffer containing $0.0625 \mathrm{M}$ Tris- $\mathrm{HCl}(\mathrm{pH} 6.8)$, $10 \%$ glycerol, $2 \% \mathrm{SDS}$, and 5\% BME, for $10 \mathrm{mins}$ and then separated on 12\% SDS-PAGE gels (mini-protean; Bio-Rad, Richmond, CA, USA) at $100 \mathrm{~V}$ until the dye front reached the bottom, then transferred overnight to nitrocellulose membranes (47 mA) (Bio-Rad). Membranes were blocked with a $5 \% \mathrm{w} / \mathrm{v}$ solution of non-fat dry milk in TPBS for $2 \mathrm{~h}$ at room temperature. The blots were then probed with primary $\mathrm{Ab}$ according to the titers provided by the manufacturer. The blots were washed once with TPBS and a 1:10,000 dilution of secondary Ab (either goat anti-rabbit alkaline phosphatase or goat anti-mouse alkaline Med Oncophosphatase) (Sigma-Aldrich) was then added. The blots were developed in the alkaline 
phosphate substrate, NBT/BCIP (Promega). Ponceau $\mathrm{S}$ (Sigma-Aldrich) blot staining and Coomassie blue (Sigma-Aldrich) gel staining after transfer allowed for an assessment of efficiency of the transfer. 0.1 M TRIS, 1\% NP-40 substitute (Sigma-Aldrich), 0.01\% SDS, $1 \mu \mathrm{g} /$ $\mathrm{mL}$ Aprotinin (Roche Applied Science, Indianapolis, IN, USA), and 0.1 $\mu \mathrm{M}$ PMSF (phenylmethanesulfonylfluoride; Sigma-Aldrich) was also tested to resolve membrane proteins. Standard RIPA buffer with Triton X-100, and sodium-deoxycholate conditions and non-denaturing conditions were each used to separate hydrophobic membrane proteins. Boiling in phenol was also tested to separate membrane proteins.

\section{Cell growth/mAb internalization assays}

Plates were tested every two days, wells were pooled for MTT analysis, and relative viable cell number was determined by MTT assay of each experiment (Promega; Life Technologies, Grand Island, NY, USA) [22]. Relative MTT optical density was plotted for each time point for the 12 pooled cell values for each experiment [22]. EnzCheck Caspase-3 assay kit (Life Technologies) was used to detect apoptosis as per manufacturer's directions and pooled well samples were assessed to increase detection. mAb internalization assays were carried out as previously described with modifications [83] and cells were examined by $\mathrm{mAb}$ absorption assays and parallel SEM assays.

\section{SEM}

The SEM studies were prepared to parallel binding studies, such as the HA, and to investigate internalization of cell surface mAb. For these studies, fixation with glutarahdehyde or modified Karnovsky's fixative, 2\% paraformaldehye $/ 2 \%$ glutaraldehyde in $0.1 \mathrm{M}$ phosphate buffer was used to block biologic processes such as internalization instead of using reduced temperature. AURION Ultra Small Immunogold (AURION Biosciences Inc., Yonkers, NY, USA) was used for detection of cell surface mAb. Carbon-coated, poly-1-lysine-coated glass 13 $\mathrm{mm}$ round cover-slips were introduced into 6-well plates containing the test cell samples. Cells were incubated with $\mathrm{mAb}$ both before and after cell fixation with glutarahdehyde, which was followed with a serum-free media rinse. The serum-free media was then pipetted off. $2.5 \%$ glutaraldehyde in $0.1 \mathrm{M}$ cacodylate buffer was then added, followed by PBS ( $1 \mathrm{mM}$ phosphate buffer, $150 \mathrm{mM}$ $\mathrm{NaCl}$ ) $0.1-0.2 \%$ AURION BSA-c ${ }^{\text {TM }} 15$ mM NaN $_{3}$ pH 7.4. Prior to scanning, ultra small gold (anti-mouse IgGFc) was added for 3-4 hours and then silver enhanced with an SEEM kit and SE-LM kit as per manufacturer's directions (AURION Biosciences Inc.). Images were viewed on a Zeiss Supra 40 field emission SEM microscope.

\section{Statistical considerations}

Student's t-test was used to assess statistical validity of ELISA data points. All data points were calculated from values across 12 wells in each of three experiments performed.

HA/ELISA cell lysates assays (Table 1): A separate statistical test is carried out for each mAb compared to each control shown: isotype control, anti-mIgG mAb11.1, and anti-huIgM. Values that are bolded are statistically significant $(p<0.05)$.

Molecular constructs-immunogens: Statistical significance is measured for molecular constructimmonogens relative to their respective control for each target tested, including PD (of m-mIgM or g-mIgG), mIgM, KLH, MAP, Perfect-Focus ${ }^{\mathrm{TM}}$ (Perfect FOCUS $^{\mathrm{TM}}$ cell extract), and IA.

Biological specimens ELISA: Statistical tests were performed comparing the mAbs to polyclonal anti-huIgM reagent (Table 1, last column).

Inhibition of direct $\mathrm{mAb}$ binding to PerfectFocus $^{\mathrm{TM}}$ assay: Statistical significance was calculated using comparisons of mIgM-PD, KLH-mIgM-PD, and Perfect-Focus + IA, each in a test of mAb-HRP reactivity pre-blocked by unlabeled excess mAb (e.g., mAb1-HRP was blocked by unlabeled $\mathrm{mAb} 1$ and similar results were found for each HRP-labeled $\mathrm{mAb}$ by its partner $\mathrm{mAb}$ ). Serum tested included Waldenstrom's Macroglobulenemia serum (W-Ms) that contained $4.2 \mathrm{~g} / \mathrm{dL}$ IgM, CLL serum that contained $22 \mathrm{mg} / \mathrm{dL}$ of IgM, and DLBCL Indolent non-Hodgkin's lymphoma (iNHL).

\section{CONFLICTS OF INTEREST}

Sydney Welt, David Kostyal, are directors and board members of Welt Bio-Molecular Pharmaceutical LLC, Yamuna D Gangadharan is employee of Welt BioMolecular Pharmaceutical LLC, Virginia Raymond is director, board member of Biogent LLC. No potential conflicts of interests were disclosed by the other authors.

\section{GRANT NUMBER}

\section{R43AI081332 - 01A1; SBIR PHASE I.}

\section{REFERENCES}

1. Miller RA, Maloney DG, Warnke R, and Levy R. Treatment of $\mathrm{B}$ cell lymphoma with monoclonal anti-idiotype antibody. N Engl J Med. 1982; 306: 517-22.

2. Levy R, and Miller R. Therapy of lymphoma directed as idiotypes. J Natl Cancer Inst Monographs. 1990; 10: 61.

3. van Endert PM, Heilig B, Hämmerling GJ, and Moldenhauer G. Monoclonal antibodies to idiotype inhibit in vitro growth of human B-cell lymphomas. Blood. 1992; 
79: 129-37.

4. Vuist WM, Levy R, and Maloney DG. Lymphoma regression induced by monoclonal anti-idiotypic antibodies correlates with their ability to induce Ig signal transduction and is not prevented by tumor expression of high levels of bcl-2 protein. Blood. 1994; 83: 899-06.

5. Tutt AL, French RR, Illidge TM, Honeychurch J, McBride HM, Penfold CA, Fearon DT, Parkhouse RM, Klaus GG, and Glennie MJ. Monoclonal antibody therapy of B cell lymphoma: signaling activity on tumor cells appears more important than recruitment of effectors. J Immunol. 1998; 16: 3176-85.

6. Marches R, Scheuermann RH, and Uhr JW. Cancer dormancy: role of cyclin-dependent kinase inhibitors in induction of cell cycle arrest mediated via membrane IgM. Cancer Res. 1998; 58: 691-7.

7. Cragg MS, Zhang L, French RR, and Glennie MJ. Analysis of the interaction of monoclonal antibodies with surface IgM on neoplastic B-cells. Br J Cancer. 1999; 79: 850-7.

8. Davis TA, Maloney DG, Czerwinshi DK, Liles TM, and Levy R. Anti-Idiotope antibodies can induce long term complete remissions in Non-Hodgkins Lymphoma without eradicating the malignant clone. Blood. 1998; 92: 1184-90.

9. Carroll WL, Lowder JN, Streifer R, Warnke R, Levy S, and Levy R. Idiotype variant cell populations in patients with B cell lymphoma. J Exp Med. 1986; 164: 1566-80.

10. Weiner GJ, and Kaminski MS. Idiotype variants emerging after anti-idiotype monoclonal antibody therapy of a murine B cell lymphoma. J Immunol. 1989; 142: 343-51.

11. Berinstein N, Campbell MJ, Lam K, Carswell C, Levy S, and Levy R. Idiotypic variation in a human B lymphoma cell line. J Immunol. 1990; 144: 752-8.

12. Kienle D, Benner A, Kröber A, Winkler D, Mertens D, Bühler A, Seiler T, Jäger U, Lichter P, Döhner H, and Stilgenbauer S. Distinct gene expression patterns in chronic lymphocytic leukemia defined by usage of specific $\mathrm{VH}$ genes. Blood. 2006; 107: 2090-3.

13. Girurajan M, Jennings CD, and Bondada S. Cutting Edge: constitutive B cell receptor signaling is critical for basal growth of B lymphoma. J Immunol. 2006; 15: 5715-9.

14. Patterson HC, Kraus M, Kim YM, Ploegh H, and Rajewski $\mathrm{K}$. The B cell receptor promotes B cell activation and proliferation through a non-ITAM tyrosine in the Ig $\alpha$ cytoplasmic domain. Immunity. 2006; 25: 55-65.

15. Chaturvedi A, Martz R, Dorward D, Waisberg M, and Pierce SK. Endocytosed BCRs sequentially regulate MAPK and Akt signaling pathways from intracellular compartments. Nat Immunol. 2011; 12: 1119-26. Erratum in: Nat Immunol. 2012 Feb 1; 13: 196.

16. Wang ML, Rule S, Martin P, Goy A, Auer R, Kahl BS, Jurczak W, Advani RH, Romaguera JE, Williams ME, Barrientos JC, Chmielowska E, Radford J, et al. Targeting BTK with Ibrutinib in relapsed or refractory Mantle-Cell Lymphoma. N Engl J Med 2013; 369: 507-16.
17. Byrd JC, Furman RR, Coutre SE, Flinn IW, Burger JA, Blum KA, Grant B, Sharman JP, Coleman M, Wierda WG, Jones JA, Zhao W, Heerema NA, et al. Targeting BTK with Ibrutinib in relapsed Chronic Lymphocytic Leukemia. N Engl J Med. 2013; 369: 32-42.

18. Woyach JA, Furman RR, Liu TM, Ozer HG, Zapatka M, Ruppert AS, Xue L, Li DH, Steggerda SM, Versele M, Dave SS, Zhang J, Yilmaz AS, et al. Resistance mechanisms for the Bruton's Tyrosine Kinase inhibitor Ibrutinib. N Engl J Med. 2014; 370: 2286-94.

19. Baracho GV, Miletic AV, Omori SA, Cato MH, and Rickert RC. Emergence of the PI3-kinase pathway as a central modulator of normal and aberrant B cell differentiation. Curr Opin Immunol. 2011; 23: 178-83.

20. Gopal AK, Kahl BS, de Vos S, Wagner-Johnston ND, Schuster SJ, Jurczak WJ, Flinn IW, Flowers CR, Martin P, Viardot A, Blum KA, Goy AH, Davies AJ, et al. PI3K $\delta$ inhibition by Idelalisib in patients with relapsed indolent lymphoma. N Engl J Med. 2014; 370: 1008.

21. Poggianella M, Bestagno $M$, and Burrone OR. The extracellular membrane-proximal domain of human membrane IgE controls apoptotic signaling of the B cell receptor in the mature B cell line A20. J Immunol. 2006; 177: 3597-605.

22. Kostyal D, Welt RS, Danko J, Shay T, Lanning C, Horton $\mathrm{K}$, and Welt S. Trastuzumab and Lapatinib modulation of HER2 tyrosine/threonine phosphorylation and cell signaling. Med Oncol. 2012; 29: 1486-94.

23. Reth M. Antigen receptor tail clue. Nature. 1989; 338: 383 4.

24. Depoil D, Fleire S, Treanor BL, Weber M, Harwood NE, Marchbank KL, Tybulewicz VL, and Batista FD. CD19 is essential for B cell activation by promoting B cell receptorantigen microcluster formation in response to membranebound ligand. Nature Immunol. 2008; 9: 63-72.

25. Pierce A. The constant region of the membrane immunoglobulin mediates B cell-receptor clustering and signaling in response to membrane antigens. Immunity. 2009; 30: 44-55.

26. Tolar P, Hanna J, Krueger PD, and Susan K. Chronic active B-cell-receptor signalling in diffuse large B-cell lymphoma. Nature 2010; 463: 88-92.

27. Tolar P, and Pierce SK. Conformation-induced oligomerization model for B cell receptor microclustering and signaling. Curr Top Microbiol Immunol. 2010; 340: 155-69.

28. Welt RS, Gangadharan YD, Welt JA, Raymond V, Kostyal D, and Welt S. Antibody-mediated modulation of the IgM B-cell receptor (BCR) expression and signaling. J Clin Oncol. 2014; 32: 5s (suppl; abstr 3050).

29. Franken NP, Rodermond HM, Stap J, Haveman J, and van Bree C. Clonogenic assay of cells in vitro. Nature Protocols. 2006; 1: 2315-9.

30. Kikushige Y, Ishikawa F, Miyamoto T, Shima T, Urata S, 
Yoshimoto G, Mori Y, Iino T, Yamauchi T, Eto T, Niiro H, Iwasaki H, Takenaka K, et al. Self-renewing hematopoietic stem cell is the primary target in pathogenesis of human chronic lymphocytic leukemia. Cancer Cell. 2011; 20: 24659.

31. Taylor RC, Cullen SP, and Martin SJ. Apoptosis: controlled demolition at cellular level. Nat Rev Mol Biol. 2008; 9: 231-41.

32. Feldhahn N, Klein F, Mooster JL, Hadweh P, Sprangers M, and Wartenberg M. Mimicry of a constitutively active pre-B cell receptor in acute lymphoblastic leukemia cells. J Exp Med. 2005; 201: 1837-52.

33. Muzio M, Apolloio B, and Scielzo C. Constitutive activation of distinct BCR-signaling pathways in a subset of CLL patients: a molecular signature of anergy. Blood. 2008; 112: 188-95.

34. Packham G, and Stevenson F. The role of the B-cell receptor in the pathogenesis of chronic lymphocytic leukaemia. Semin Cancer Biol. 2010; 20: 391-9.

35. Young RM, and Staudt LM. Targeting pathological B cell receptor signalling in lymphoid malignancies. Nat Rev Drug Discov. 2013; 12: 229-43.

36. Boukhiar MA, Roger C, Tran J, Gressin R, Martin A, and Ajchenbaum-Cymbalista F. Targeting early B-cell receptor signaling induces apoptosis in leukemic mantle cell lymphoma. Exp Hematol Oncol. 2013; 2: 3619-23.

37. Niemann CU, and Wiestner A. B-cell receptor signaling as a driver of lymphoma development and evolution. Semin Cancer Biol. 2013; 23: 410-21.

38. Hamblin TJ, Davis Z, Gardiner A, Oscier DG, and Stevenson FK. Unmutated $\mathrm{Ig} \mathrm{V}(\mathrm{H})$ genes are associated with a more aggressive form of chronic lymphocytic leukemia. Blood. 1999; 94: 1848-54.

39. Messmer BT, Albesiano E, Efremov DG, Ghiotto F, Allen SL, Kolitz J, Foa R, Damle RN, Fais F, Messmer D, Rai KR, Ferrarini M, and Chiorazzi N. Multiple distinct sets of stereotyped antigen receptors indicate a role for antigen in promoting chronic lymphocytic leukemia. J Exp Med. 2004; 200: 519-25.

40. Tobin G, Thunberg U, Karlsson K, Murray F, Laurell A, Willander K, Enblad G, Merup M, Vilpo J, Juliusson G, Sundström C, Söderberg O, Roos G, et al. Subsets with restricted immunoglobulin gene rearrangement features indicate a role for antigen selection in the development of chronic lymphocytic leukemia. Blood. 2004; 104: 2879-85.

41. Hartmann EM, and Rosenwald A. Chronic lymphocytic leukemia with mutated IgVH1-69 usage: A distinct CLL subgroup with more indolent behavior? Leuk Lymphoma Commentary. 2008; 49: 648-9.

42. Kharfan-Dabaja MA, Chavez JC, Khorfan KA, and Pinilla-Ibarz J. Clinical and therapeutic implications of the mutational status of IgVH in patients with chronic lymphocytic leukemia. Cancer. 2008; 113: 897-906.

43. Dühren-von Minden M, Übelhart R, Schneider D, Wossning
T, Bach MP, Buchner M, Hofmann D, Surova E, Follo M, Köhler F, Wardemann H, Zirlik K, Veelken H, et al. Chronic lymphocytic leukaemia is driven by antigenindependent cell-autonomous signaling. Nature. 2012; 489: 309-12.

44. Agathangelidis A, Darzentas N, Hadzidimitriou A, Brochet X, Murray F, Yan XJ, Davis Z, van Gastel-Mol EJ, Tresoldi C, Chu CC, Cahill N, Giudicelli V, Tichy B, et al. Stereotyped B-cell receptors in one-third of chronic lymphocytic leukemia: a molecular classification with implications for targeted therapies. Blood. 2012; 119: 446775.

45. Wiestner A. BCR pathway inhibition as therapy for chronic lymphocytic leukemia and lymphoplasmacytic lymphoma. Hematology Am Soc Hematol Educ Program. 2014; 5: 12534.

46. Burger JA, Ghia P, Rosenwald A, and Caligaris-Cappio F. The microenvironment in mature B-cell malignancies: a target for new treatment strategies. Blood. 2009; 114: 336775.

47. Herishanu Y, Pérez-Galán P, Liu D, Biancotto A, Pittaluga S, Vire B, Gibellini F, Njuguna N, Lee E, Stennett L, and Raghavachari N. The lymph node microenvironment promotes B-cell receptor signaling, NF- $\mathrm{B}$ activation, and tumor proliferation in chronic lymphocytic leukemia. Blood. 2011; 117: 563-74.

48. Medina D, Goodell L, Glod J, Gelinas C, Rabson A, and Strair R. Mesenchymal stromal cells protect mantle cell lymphoma cells from spontaneous and drug-induced apoptosis through secretion of B-cell activating factor and activation of the canonical and non-canonical nuclearfactor кB pathways. Haematologica. 2012; 97: 1255-63.

49. Faustin P, Etet S, Vecchio L, Hervé A, and Kamdje $\mathrm{N}$. Interactions between bone marrow stromal microenvironment and B-chronic lymphocytic leukemia cells: Any role for Notch, Wnt and Hh signalling pathways. Cellular Signaling. 2012; 24: 1433-43.

50. Shukla A, Chaturvedi NK, Ahrens AK, Cutucache CE, Mittal AK, Bierman P, Weisenburger DD, Lu R, and Joshi SS. Stromal tumor microenvironment in Chronic Lymphocytic Leukemia: regulation of leukemic progression. J Leuk. 2013; 1: 113.

51. Herishanu Y, Katz BZ, Lipsky A, and Wiestner A. Biology of Chronic Lymphocytic Leukemia in different microenvironments: clinical and therapeutic implications. Hematol Oncol Clin North Am. 2013; 27: 173-206.

52. Bernard S, Danglade D, Gardano L, Laguillier C, Lazarian G, Roger C, Thieblemont C, Marzec J, Gribben J, Cymbalista F, Varin-Blank N, Ledoux D, and BaranMarszak F. Inhibitors of BCR signalling interrupt the survival signal mediated by the micro-environment in mantle cell lymphoma. Int J Cancer. 2015; 136: 2761-74.

53. Woyach JA, Smucker K, Smith LL, Lozanski A, Zhong Y, Ruppert AS, Lucas D, Williams K, Zhao W, Rassenti L, Ghia E, Kipps TJ, Mantel R, et al. Prolonged lymphocytosis 
during ibrutinib therapy is associated with distinct molecular characteristics and does not indicate a suboptimal response to therapy. Blood. 2014; 123: 1810-7.

54. Chang BY, Francesco M, De Rooij MF, Magadala P, Steggerda SM, Huang MM, Kuil A, Herman SE, Chang S, Pals ST, Wilson W, Wiestner A, Spaargaren M, et al. Egress of CD19+CD5+ cells into peripheral blood following treatment with the Bruton tyrosine kinase inhibitor ibrutinib in mantle cell lymphoma patients. Blood. 2013; 122: 2412 24.

55. Westin JR, Kantarjian H, and Kurzrock R. Treatment of chronic myelogenous leukemia as a paradigm for solid tumors: how targeted agents in newly diagnosed disease transformed outcomes. Am Soc Clin Oncol Educ Book. 2012; 179-85.

56. Davis RE, Ngo VN, Lenz G, Tolar P, Young RM, Romesser PB, Kohlhammer H, Lamy L, Zhao H, Yang Y, Xu W, Shaffer AL, Wright G, et al. Chronic active B-cell-receptor signalling in diffuse large B-cell lymphoma. Nature. 2010; 463: 88-92.

57. Carter RH, Doody GM, Bolen JB, and Fearon DT. Membrane IgM-induced tyrosine phosphorylation of CD19 requires a CD19 domain that mediates association with component of the B cell receptor complex. J Immunol. 1997; 158: 3062-9.

58. Chan VM, Meng F, Soriano P DeFranco AL, and Lowell CA. Characterization of the B lymphocyte populations in Lyn deficient mice and the role of Lyn signal initiation and down regulation. Immunity. 1997; 7: 69-81.

59. Nashizumi H, Horikawa K, Mlinaric-Rascan I, and Yamamoto T. A double-edged kinase Lyn: a positive and negative regulator for antigen receptor-mediated signals. $\mathrm{J}$ Exp Med. 1998; 187: 1343-8.

60. Srinivasan L, Sasaki Y, Calado DP, Zhang B, Paik JH, DePinho RA, Kutok JL, Kearney JF, Otipoby KL, and Rajewsky K. PI3 kinase signals BCR dependent mature B cell survival. Cell. 2009; 139: 573-86.

61. Baracho GV, Miletic AV, Omori SA, Cato MH, and Rickert RC. Emergence of the PI3-kinase pathway as a central modulator of normal and aberrant B cell differentiation. Curr Opin Immunol. 2011; 23: 178-83.

62. Bachmann MF, Nitschke L, Krawczyk C, Tedford K, Ohashi PS, Fischer KD, and Penninger JM. The guaninenucleotide exchange factor $\mathrm{Vav}$ is a crucial regulator of $\mathrm{B}$ cell receptor activation and $\mathrm{B}$ cell responses to nonrepetitive antigens. J Immunol. 1999; 163: 137-42.

63. Ishiura N, Nakashima H, Watanabe R, Kuwano Y, Adachi T, Takahashi Y, Tsubata T, Okochi H, Tamaki K, Tedder $\mathrm{TF}$, and Fujimoto M. Differential phosphorylation of functional tyrosines in CD19 modulates B-lymphocyte activation. Eur J Immunol. 2010; 40: 1192-204.

64. Doody GM, Justement LB, Delibrias CC, Mathews RL, Lin $\mathrm{J}$, Thomas ML, and Fearon DT. A role in B cell activation for $\mathrm{CD} 22$ and the protein tyrosine phosphatase SHP.
Science. 1995; 269: 242-4

65. O'Keefe TL, Williams GT, Davies SL, and Neuberger MS Hyperresponsive B cells in CD22-deficient mice. Science. 1996; 274: 798-801.

66. Otipoby KL, Andersson KB, Draves KE, Klaus SJ, Farr AG, Kerner JD, Perlmutter RM, Law CL, and Clark EA. $\mathrm{CD} 22$ regulates thymus-independent response and the lifespan of B cells. Nature. 1996; 384: 634-7.

67. Sato S, Miller AS, Howard MC, and Tedder TF. Regulation of B lymphocyte development and activation by the CD19/ CD21/CD81/Leu13 complex requires the cytoplasmic domain of CD19. J Immunol. 1997; 159: 3278-87.

68. Smith KGC, Tarlinton DM, Doody GM, Hibbs ML, and Fearon DT. Inhibition of B-cell by CD22: a requirement for Lyn. J Exp Med. 1998; 187: 807-11.

69. Smith KG, and Fearon DT. Receptor modulators of B-cell receptor signaling-CD19/22. Curr Top Microbiol Immunol. 2000; 245: 195-212.

70. Lyubchenko T, Porto J, Cambier JC, and Holers VM. Coligation of the $\mathrm{B}$ cell receptor with complement receptor type 2 (CR2/CD21) using its natural ligand C3dg: activation without engagement of an inhibitory signaling pathway. J Immunol. 2005; 174: 3264-77.

71. Lee Y, Haas KM, Gor DO, Ding X, Karp DR, Greenspan NS, Poe JC, and Tedder TF. Complement component C3d-antigen complexes can either augment or inhibit B lymphocyte activation and humoral immunity in mice depending on the degree of CD21/CD19 complex engagement. J Immunol. 2005; 175: 8011-23.

72. Polson AG, Calemine-Fenaux J, Chan P, Chang W, Christensen E, Clark S, de Sauvage FJ, Eaton D, Elkins K, Elliott JM, Frantz G, Fuji RN, Gray A, et al. Antibody-drug conjugates for the treatment of non-Hodgkin's lymphoma: target and linker-drug selection. Cancer Res. 2009; 69: 2358-64.

73. Farooqui MZ, Valdez J, Martyr S, Aue G, Saba N, Niemann CU, Herman SE, Tian X, Marti G, Soto S, Hughes TE, Jones J, Lipsky A, et al. Ibrutinib for previously untreated and relapsed or refractory chronic lymphocytic leukaemia with TP53 aberrations: a phase 2, single-arm trial. Lancet Oncol. 2015; 16: 169-76.

74. Kochenderfer JN, Feldman SA, Zhao Y, Xu H, Black MA, Morgan RA, Wilson WH, and Rosenberg SA. Construction and pre-clinical evaluation of an anti-CD19 chimeric antigen receptor. J Immunother. 2009; 32: 689-702.

75. Hoffman LM, and Gore L. Blinatumomab, a bi-specific anti-CD19/CD3 BiTE® antibody for the treatment of acute lymphoblastic leukemia: perspectives and current pediatric applications. Front Oncol. 2014; 4: 63.

76. Yang YF, Chou MY, Fan CY, Chen SF, Lyu PC, Liu CC, and Tseng TL. The possible interaction of CDA14 and protein elongation factor $1 \alpha$. BBA-Proteins Proteom. 2008; 1784: 312-8. 
77. Yin BW, Finstad CL, Kitamura K, Federici MG, Welshinger M, Kudryashov V, Hoskins WJ, Welt S, and Lloyd KO. Serological and immunochemical analysis of Lewis Y (Ley) blood group antigen expression in epithelial ovarian cancer. Int J Cancer. 1996; 65: 406-12.

78. Feichtner S, Inführ D, Achatz-Straussberger G, Schmid D, Karnowski A, Lamers M, Rhyner C, Crameri R, and Achatz G. Targeting the extra-cellular membrane proximal domain of membrane-bound IgE by passive immunization blocks IgE synthesis in vivo. J Immunol. 2008; 180: 5499-505.

79. Chen JB, Wu PC, Hung AF, Chu CY, Tsai TF, and Yung HM. Unique epitopes on CemX in IgE-B cell receptors are potentially applicable for targeting IgE-committed B cells. J Immunol. 2010; 184: 1748-56.

80. Carey TE, Takahashi T, Resnick LA, Oettgen HF, and Old LJ. Cell surface antigens of human malignant melanoma: mixed hemadsorption assays for humoral immunity to cultured autologous melanoma cells. Proc Natl Acad Sci U S A.1976; 73: 3278-82.
81. O’Boyle KP, Markowitz AL, Khorshidi M, Lalezari P, Longenecker BM, Lloyd KO, Welt S, and Wright KE. Specificity analysis of murine monoclonal antibodies reactive with $\mathrm{Tn}$, sialylated $\mathrm{Tn}, \mathrm{T}$, and monosialylated $(2 \rightarrow 6)$ T antigens. Hybridoma. 1996; 15: 401-8.

82. Rader C, Ritter G, Nathan S, Elia M, Gout I, Jungbluth AA, Cohen LS, Welt S, Old LJ, and Barbas CF. The rabbit antibody repertoire as a novel source for the generation of therapeutic human antibodies. J Biol Chem. 2000; 275: 13668-76.

83. Daghighian F, Barendswaard E, Welt S, Humm J, Scott A, and Willingham MC. Enhancement of radiation dose to the nucleus by vesicular internalization of iodine-125-labeled A33 monoclonal antibody. J Nucl Med. 1996; 37: 1052-7. 